\title{
Temperature dependence of yields of secondary organic aerosols from the ozonolysis of $\alpha$-pinene and limonene
}

\author{
H. Saathoff ${ }^{1}$, K.-H. Naumann ${ }^{1}$, O. Möhler ${ }^{1}$, Å. M. Jonsson ${ }^{2}$, M. Hallquist ${ }^{2}$, A. Kiendler-Scharr ${ }^{3}$, Th. F. Mentel ${ }^{3}$, \\ R. Tillmann ${ }^{3}$, and U. Schurath ${ }^{1}$ \\ ${ }^{1}$ Institute for Meteorology and Climate Research, Forschungszentrum Karlsruhe, Hermann-von-Helmholtz-Platz 1, \\ 76344 Eggenstein-Leopoldshafen, Germany \\ ${ }^{2}$ Department of Chemistry, Atmospheric Science, University of Gothenburg, 41296 Göteborg, Sweden \\ ${ }^{3}$ Institute of Chemistry and Dynamics of the Geosphere 2, Forschungszentrum Jülich, 52425 Jülich, Germany
}

Received: 15 July 2008 - Published in Atmos. Chem. Phys. Discuss.: 15 August 2008

Revised: 5 February 2009 - Accepted: 5 February 2009 - Published: 3 March 2009

\begin{abstract}
Secondary organic aerosol (SOA) formation has been investigated as a function of temperature and humidity for the ozone-initiated reaction of the two monoterpenes $\alpha$-pinene (243-313 K) and limonene (253-313 K) using the $84.5 \mathrm{~m}^{3}$ aerosol chamber AIDA. This paper gives an overview of the measurements done and presents parameters specifically useful for aerosol yield calculations. The ozonolysis reaction, selected oxidation products and subsequent aerosol formation were followed using several analytical techniques for both gas and condensed phase characterisation. The effective densities of the SOA were determined by comparing mass and volume size distributions to $(1.25 \pm 0.10) \mathrm{g} \mathrm{cm}^{-3}$ for $\alpha$-pinene and $(1.3 \pm 0.2) \mathrm{g} \mathrm{cm}^{-3}$ for limonene. The detailed aerosol dynamics code COSIMASOA proved to be essential for a comprehensive evaluation of the experimental results and for providing parameterisations directly applicable within atmospheric models. The COSIMA-assisted analysis succeeded to reproduce the observed time evolutions of SOA total mass, number and size distributions by adjusting the following properties of two oxidation product proxies: individual yield parameters $\left(\alpha_{i}\right)$, partitioning coefficients $\left(K_{i}\right)$, vapour pressures $\left(p_{i}\right)$ and effective accommodation coefficients $\left(\gamma_{i}\right)$. For these properties temperature dependences were derived and parameterised. Vapour pressures and partitioning coefficients followed classical Clausius - Clapeyron temperature dependences. From this relationship enthalpies of vaporisation were derived for the two more and less volatile product proxies of $\alpha$-pinene: $(59 \pm 8) \mathrm{kJ} \mathrm{mol}^{-1}$ and $(24 \pm 9) \mathrm{kJ} \mathrm{mol}^{-1}$, and limonene: $(55 \pm 14) \mathrm{kJ} \mathrm{mol}^{-1}$ and $(25 \pm 12) \mathrm{kJ} \mathrm{mol}^{-1}$. The more volatile proxy components had a notably low enthalpy
\end{abstract}

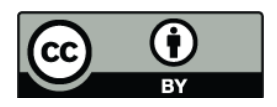

Correspondence to: $\mathrm{H}$. Saathoff (harald.saathoff@imk.fzk.de) of vaporisation while the less volatile proxy components gave enthalpies of vaporisation comparable with those of typical products from $\alpha$-pinene oxidation, e.g. pinonaldehyde and pinonic acid.

\section{Introduction}

Biogenic sources dominate the global emissions of volatile organic compounds into the atmosphere. The annual emissions of biogenic volatile organic compounds (BVOC) without methane are estimated to range from 491 to $1150 \mathrm{Tg}$ carbon, up to an order of magnitude more than the estimated emissions from anthropogenic sources (Müller, 1992; Guenther et al., 1995). Almost half of the BVOC mass emitted is isoprene and about $11 \%$ are monoterpenes of which the highest fractions are $\alpha$-pinene (25\%) and limonene (16\%) (Kanakidou et al., 2005). Although isoprene is the most abundant BVOC its contribution to the formation of SOA has still a high uncertainty with estimated global annual aerosol masses ranging from 10 to $120 \mathrm{Tg}$ (Matsunaga et al., 2005). The ozonolysis of monoterpenes is supposed to be one major source of secondary organic aerosol (SOA) (Griffin et al., 1999b). The importance of monoterpene oxidation to ambient SOA is further emphasised by observations of typical oxidation products from $\alpha$-pinene oxidation e.g. pinonaldehyde, pinic and pinonic acids in ambient aerosol (Calogirou et al., 1999; Yu et al., 1999b; Plewka et al., 2006; Cahill et al., 2006). Global transport models predict a substantial chemical production of organic aerosol in the free troposphere (Tsigaridis et al., 2005) and project an even higher fraction of SOA from oxidation of monoterpenes in future scenarios (Tsigaridis and Kanakidou, 2007). However, the formulation of SOA formation and chemical composition in

Published by Copernicus Publications on behalf of the European Geosciences Union. 
these models needs to be improved. Recent field measurements demonstrate that SOA is a dominant fraction of aerosol mass in the free troposphere and that theoretical estimations of SOA masses may be 1-2 orders of magnitude too low (Heald et al., 2005). Consequently, there have been a number of laboratory studies focusing on SOA yields, i.e. the mass of SOA produced per mass of reacted precursor. These depend mainly on the organic precursor molecules and on the oxidants initiating the degradation $\left(\mathrm{OH}, \mathrm{O}_{3}, \mathrm{NO}_{3}\right)$. However, it has also been shown that other factors influence the SOA yield, i.e. the mass of organic aerosol that can serve as solvent for semivolatile organic compounds (Pankow, 1994; Odum et al., 1996), the acidity of and chemical reactions in the particulate phase (Jang et al., 2003; Gao et al., 2004; Iinuma et al., 2004; Kalberer et al., 2004), the humidity (Bonn et al., 2002; Jonsson et al., 2006), and the temperature that controls the phase equilibrium of the semivolatile organics and also influences the reaction pathways leading to condensable molecules (Sheehan and Bowman, 2001; Takekawa et al., 2003; Jenkin, 2004; Offenberg et al., 2006; Pathak et al., 2007b; Stanier et al., 2007; Johnson and Marston, 2008). There has been a considerable amount of work on aerosol yields from the ozonolysis of $\alpha$-pinene or limonene near room temperature (290-303 K) e.g. (Hoffmann et al., 1997; Griffin et al., 1999a; Hoppel et al., 2001; Cocker et al., 2001; Berndt et al., 2003; Iinuma et al., 2004; Presto and Donahue, 2006; Northcross and Jang, 2007; Pathak et al., 2007a; Iinuma et al., 2007; Johnson and Marston, 2008; Shilling et al., 2008). Studies covering more extended temperature ranges are less abundant (Sheehan and Bowman, 2001; Takekawa et al., 2003; Offenberg et al., 2006; Pathak et al., 2007b). Obviously, temperature dependences are important in describing SOA formation under tropospheric conditions and - when properly evaluated - can improve our understanding of the physical and chemical mechanisms involved in the ozonolysis of monoterpenes. Experiments in large environmental chambers covering a large temperature range are particularly suited to derive parameterisations which are valid under real world conditions (Griffin et al., 2005; Simpson et al., 2007). The most common way of parameterising SOA data is based on a two product mass partitioning model (Pankow, 1994; Odum et al., 1996; Griffin et al., 1999a). However, it has been shown that this type of parameterisation not always gives unique and simple representations (Pathak et al., 2007a). For that purpose an option is to also use information from measured aerosol size distributions to put further constrains on the parameters included in the models (Naumann, 2009).

This paper presents investigations on the yield of SOA material from the ozonolysis of $\alpha$-pinene and limonene under simulated tropospheric conditions in the large aerosol chamber AIDA (Saathoff et al., 2003) on time scales of up to $36 \mathrm{~h}$ and at temperatures between 243 and $313 \mathrm{~K}$. The data were obtained during three measurement campaigns at the AIDA simulation chamber during October/November
2003 (SOA03), March 2005 (SOA05), and February 2006 (SOA06). The campaigns in 2005 and 2006 were accomplished in an on-site collaboration between Forschungszentrum Karlsruhe, Forschungszentrum Jülich, Leibniz Institute for Tropospheric Research Leipzig, and the University of Gothenburg. In order to evaluate the data and parameterise physical aerosol properties a dynamic SOA model was developed and applied (Naumann, 2009).

\section{Experimental}

The AIDA aerosol and cloud chamber of Forschungszentrum Karlsruhe (Saathoff et al., 2003) was used to investigate the formation of SOA at a pressure of about $1000 \mathrm{hPa}$, temperatures between 243 and $313 \mathrm{~K}$, and relative humidities with respect to water between 0.02 and $78 \%$. A typical experiment was performed with an excess concentration of ozone and step-wise addition of the organic reactant. SOA particles were generated by reacting (1S)-(-)- $\alpha$-pinene (99\%, Aldrich) and (S)-(-)-limonene (>97\%, Merck) with ozone in the dark. The simulation chamber (Fig. 1) has a total volume of $84.5 \mathrm{~m}^{3}$, an upright cylindrical shape with a total surface area of $103 \mathrm{~m}^{2}$, and a cross sectional area of $12.6 \mathrm{~m}^{2}$. Before each experiment the AIDA chamber was evacuated to typically $1 \mathrm{~Pa}$ total pressure, flushed two times with $10 \mathrm{hPa}$ of synthetic air and filled to atmospheric pressure $(\sim 1000 \mathrm{hPa})$ with humidified or dry synthetic air (low hydrocarbon grade, Basi). To inhibit interference by $\mathrm{OH}$ radicals that are formed during the ozonolysis, $500 \mathrm{ppm}$ of cyclohexane $(99.5 \%$, Merck) was added as radical scavenger. In most experiments ozone was first filled into the chamber to measure the level of background particle formation before the terpenes were added. These particles were formed typically $15-20 \mathrm{~min}$ after the addition of ozone in varying number concentrations but with negligible mass concentrations. Ozone was generated by a silent discharge generator (Semozon 030.2, Sorbios) in mixing ratios of about 3\% in pure oxygen and added to the chamber either directly or more typically after dilution to about $1 \%$ in a 1 litre glass bulb which was flushed into the chamber with a flow of 5 SLM synthetic air. Defined amounts of the terpenes were added by evaporating $2-4 \mathrm{hPa}$ into 1 and 2 litre glass bulbs, diluting them with synthetic air, and flushing the contents into the chamber with 10 SLM synthetic air for $3 \mathrm{~min}$. In most experiments the terpenes were added in subsequent steps with increasing amounts to the excess of ozone. The next portion of the terpene was introduced into the chamber after the previously added amount had been consumed. In this way the organic aerosol mass concentrations reached relatively stable values before the next portion was added. The experiments were done without special seed aerosol particles and therefore new particles were formed after the first addition of the terpene to the excess of ozone. The amount of ozone in the chamber was chosen to achieve $>95 \%$ oxidation of 


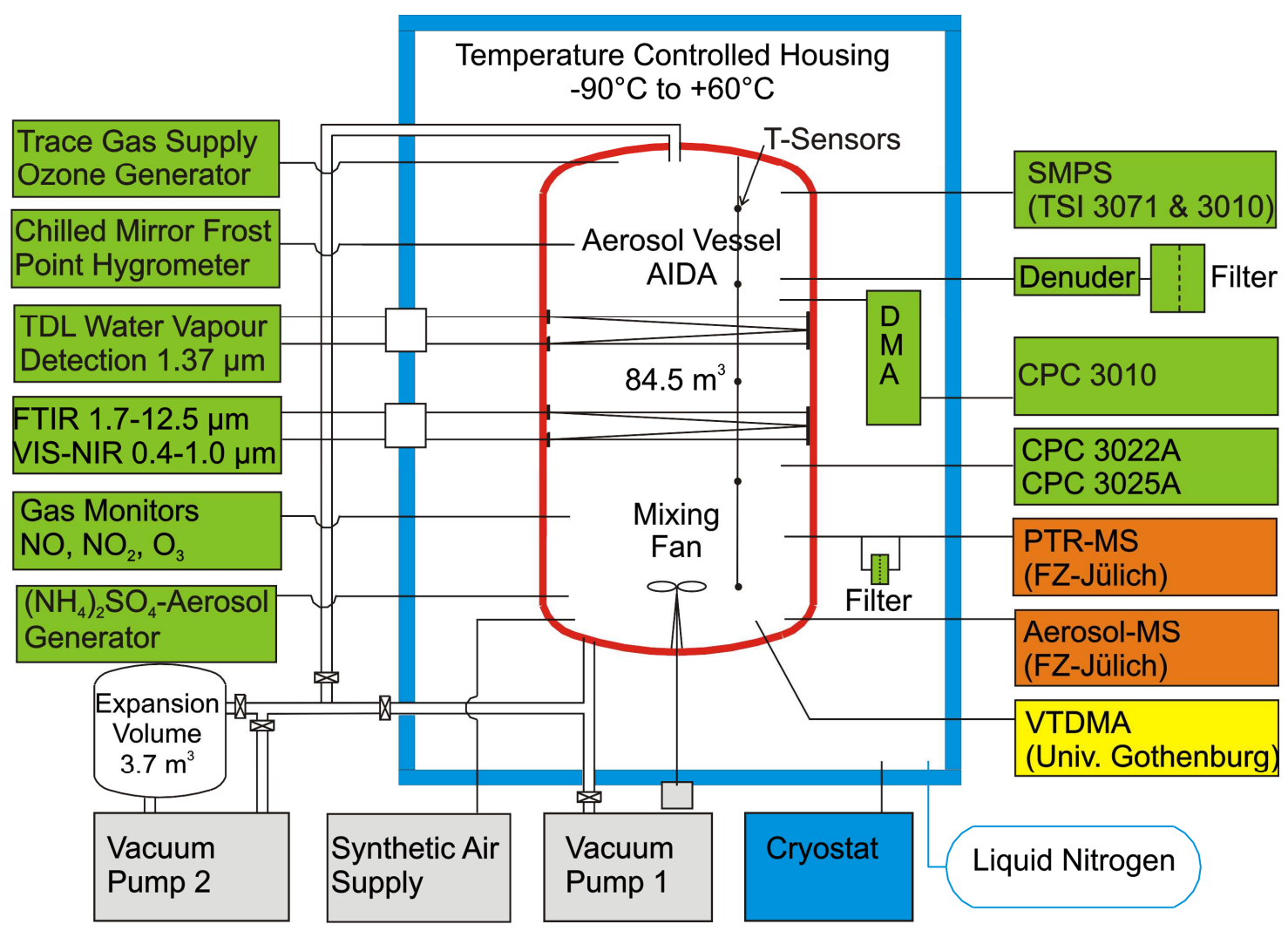

Fig. 1. Schematic of the AIDA simulation chamber with the typical instrumentation for experiments with SOA.

the terpenes within about $2 \mathrm{~h}$, but avoiding substantial new particle formation after the initial nucleation. Especially for limonene and for the coldest temperatures, it was not always possible to avoid new particle formation after the first addition, but the dominant mass fraction always condensed on the pre-existing organic aerosol. The ozone was replenished typically one or two times during the experiments to maintain the concentration levels required. Due to its excellent temperature control and large size, the AIDA chamber enabled us to make experiments at temperatures between 243 and $313 \mathrm{~K}$ and on time scales of up to $36 \mathrm{~h}$. A mixing fan in the chamber was running during all experiments providing typical $95 \%$ mixing times of $3 \mathrm{~min}$. The initial terpene concentrations, humidity ranges, and average temperatures are summarised in Tables A1 and A2. To investigate the role of the $\mathrm{OH}$ scavenger, in two experiments 2-butanol (99.5\%, Merck) was used instead of cyclohexane and three experiments were done without radical scavenger. For experiments with $\alpha$-pinene the temperature was varied between 313 and $243 \mathrm{~K}$ and for experiments with limonene between 313 and $253 \mathrm{~K}$. In most experiments the humidity was chosen to be close to or for practical reasons just a little below typical atmospheric conditions. In order to investigate the impact of water on the SOA yields the water mixing ratios were reduced to only a few ppm in some experiments.
The typical instrumentation for SOA experiments and a schematic of the AIDA chamber are shown in Fig. 1. The dilution tracer $\mathrm{SF}_{6}$, ozone and $\alpha$-pinene were measured by FTIR long path $(254 \mathrm{~m}$ ) absorption spectroscopy (IFS66/v, Bruker). Ozone was measured simultaneously with an ozone monitor (O3-41M, Environment) connected to the chamber via a Teflon tube. Water concentrations were measured with a frost point mirror hygrometer (373LX, MBW) and in situ by absorption spectroscopy using a tuneable diode laser at $1370 \mathrm{~nm}$. During the campaigns in 2005 and $2006 \alpha$-pinene, limonene, pinonaldehyde, and cylohexanone were measured with a Proton Transfer Reaction Mass Spectrometer (PTRMS, Ionicon). The PTR-MS was sampling from the AIDA chamber via a stainless steel tube $(4 \mathrm{~mm}$ inner diameter) through a Teflon filter (PTFE, $0.2 \mu \mathrm{m}$ pore size, Satorius) in the thermostated housing which could also be bypassed. The filter removed aerosol particles from the sample flow to avoid possible evaporation of aerosol particles in the inlet of the PTR-MS. The PTR-MS measurements were taken with a time resolution of $5 \mathrm{~min}$. The accuracies $(1 \sigma$-error of the sensitivities) for the detection of $\alpha$-pinene, limonene, pinonaldehyde, and cylohexanone were $\pm 6 \%, \pm 6 \%, \pm 20 \%$, and $\pm 5 \%$, respectively, during the 2005 experiments and $\pm 4 \%$, $\pm 6 \%, \pm 22 \%, \pm 5 \%$ for the 2006 experiments. 
Particle number concentrations were measured with condensation particle counters (CPC 3022A and CPC 3025A, TSI) outside the thermostated housing via stainless steel tubes extending $35 \mathrm{~cm}$ into the AIDA chamber. The absolute uncertainty of the number concentrations was estimated to $\pm 20 \%$ by comparison of the different CPCs with each other and with an electrometer (3068, TSI). Size distributions were obtained using two mobility particle sizers (DMA 3071 \& CPC 3010, TSI), one outside (SMPS) and one inside the thermostated housing (DMPS). Typical time intervals for size distribution measurements inside the thermostated housing were $25 \mathrm{~min}$ (DMPS) and outside $6 \mathrm{~min}$ (SMPS). Volume size distributions were normalised to the total number concentrations and integrated to obtain particle volume concentrations. The uncertainty of the particle volume concentrations obtained this way was estimated to $\pm 30 \%$ taking into account the uncertainty in the total number concentrations and the relative importance of the larger particles. The typical residence time of aerosol particles in the room temperature sections of the sampling lines for measurements with the CPC's and the SMPS is $2 \mathrm{~s}$. Differences between measurements with the SMPS (with DMA particle selection at room temperature) and the DMPS (with DMA particle selection at aerosol chamber temperature) were within measurement uncertainties even for the lowest temperatures in the aerosol chamber. Nevertheless, the SMPS results were normalised to the DMPS data to correct for potential particle losses due to evaporation. The particle mass and composition was measured with an aerosol mass spectrometer (QAMS, Aerodyne) connected via a stainless steel tube to the simulation chamber. The sampling tube was kept at AIDA temperature up to the inlet valve of the AMS. AMS measurements were taken with a time resolution of $5 \mathrm{~min}$. Comparison of mass size distributions (AMS) with volume size distributions (DMA) was used for SOA density evaluation. Changes in particle volatility were measured with a volatility tandem differential mobility analyser (VTDMA). This instrument and the main results of the volatility measurements are described in a recent publication (Jonsson et al., 2007). SOA particles were also collected on Teflon filters (PTFE, $47 \mathrm{~mm}$ diameter, $0.2 \mu \mathrm{m}$ pore size, Satorius) via stainless steel tubes. Before the filter annular denuders coated with vacuum grease (Apiezon $\mathrm{L}$ ) were used to remove gaseous organics. The filters were extracted with $6 \mathrm{ml}$ of methanol and analysed by e.g. CE-MS. Details of the analysis method can be found elsewhere (Iinuma et al., 2004). If not stated otherwise uncertainties reported in this paper correspond to values of two sigma.

\section{Modelling}

In order to provide a flexible framework for the detailed analysis of the experiments outlined above, the sectional aerosol behaviour code COSIMA (Naumann, 2003) has been ex- tended to simulate the formation and dynamics of secondary organic aerosol systems in chambers (Naumann, 2009). The physical aerosol processes treated in COSIMA-SOA include particle diffusion to the walls and sedimentational deposition, coagulation, condensation and evaporation, wall losses of trace gases and dilution effects due to sampling. The chamber wall is assumed to act as an irreversible sink for particles and trace gases. Transport of trace gas molecules to and away from the particle surface is modelled kinetically under consideration of the Kelvin effect. Therefore, non-equilibrium situations, e.g. due to transport limitations, are properly accounted for. Dahneke's approach was employed to interpolate between the continuum and free molecular regimes (Dahneke, 1983). Since the current version of the model does not explicitly account for nucleation, simulations are initialised with a measured size distribution or by feeding a well defined particle mode into the control volume over a time interval corresponding to the experimental observation of new particle formation.

Detailed reaction schemes for the gas phase oxidation of $\alpha$-pinene and limonene over the whole range of temperatures between 243 and $313 \mathrm{~K}$ are not available. COSIMASOA so far simply assumes the formation of a certain number of effective reaction products from a given set of precursors. There is no principal limitation regarding the number of educts and products considered in the model. For each product $i$ partitioning into the condensed phase the following properties have to be specified: molar mass $M W_{i}$, mass stoichiometric yield $\alpha_{i}$, bulk vapour pressure $p_{i}^{0}$, mass density $\rho_{i}$, surface tension $\sigma_{i}$, gas phase diffusivity $D_{i}$, effective accommodation coefficient $\gamma_{i}$, and a rate constant $k_{i}$ for its first order wall loss. Thermodynamically the condensed phase is treated as an ideal organic mixture since any extrapolation of e.g. activity prediction schemes like UNIFAC (Fredenslund et al., 1977) down to temperatures as low as $243 \mathrm{~K}$ is associated with great uncertainties. While the chemical composition may vary with particle size, all particles within a given size bin are assumed to be equally composed.

The temperature dependent rate coefficients for the ozonolysis of $\alpha$-pinene were taken from the work of Atkinson (Atkinson et al., 1982; Atkinson, 1997). For the simulations of the limonene ozonolysis the rate coefficient and corresponding temperature dependence reported by Khamaganov and Hites (Khamaganov and Hites, 2001) was used. Based on this, the time evolutions of the reactant and gaseous product concentrations as well as particle size distribution, mass and number concentrations were calculated and compared to the respective experimental results. This intercomparison allowed to establish the minimum number of effective product compounds required to reproduce the measured data within the experimental uncertainty and to determine the properties of the reaction products partitioning into the condensed phase.

While the kinetic modelling of product partitioning between gas and particulate phase allows to account for 


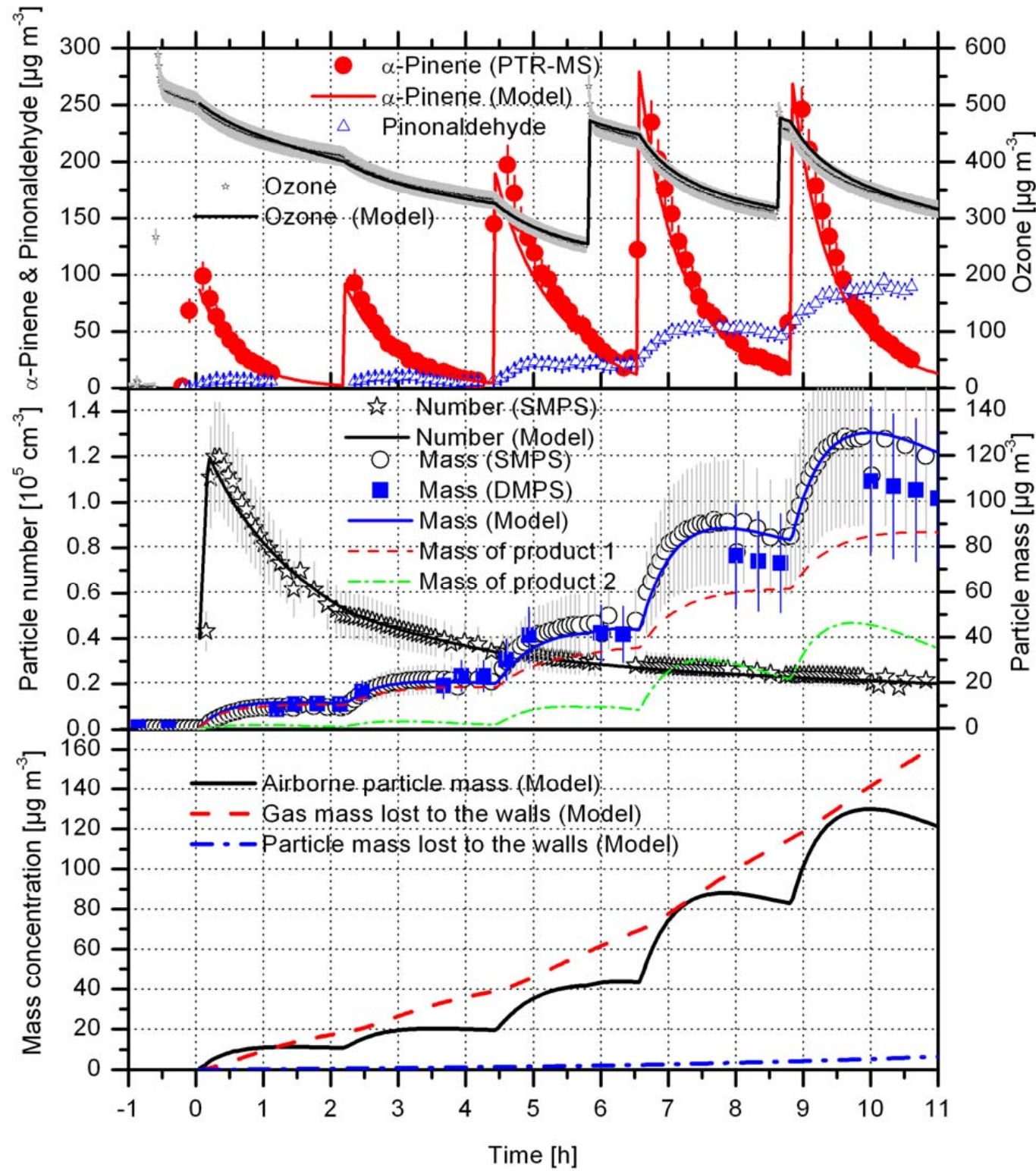

Fig. 2a. Evolution of measured trace gas, particle number, and mass concentrations (symbols) and model results including wall losses (lines) for experiment SOA05-2 at $303 \mathrm{~K}$.

non-equilibrium behaviour, it may significantly increase the numerical effort to be dealt with during the simulation runs. Therefore, a large amount of work still relies on the assumption that in the course of SOA formation equilibrium is rapidly established between the gas and the condensed phase. A very popular and convenient concept has been devised by Pankow, see e.g. (Seinfeld and Pankow, 2003). In this $K-\alpha$ approach the aerosol yield $Y=M_{o} / \Delta M_{\text {Terpene }}$ is given by

$Y=\sum_{i} Y_{i}=M_{0} \sum_{i} \frac{\alpha_{i} K_{i}}{1+K_{i} M_{0}}$ where $M_{0}$ represents the particle mass concentration produced from the reacted fraction $\Delta M_{\text {Terpene }}$ of the total precursor mass concentration $M_{\text {Terpene }}$ and $K_{i}$ denotes the equilibrium gas phase/particle partitioning coefficient of component $i$. The fact that complex chemical processes - from the initial terpene oxidation step to the formation of condensable products - determine the yields of the individual product masses $M_{i}$ is accounted for by defining mass based stoichiometric yield coefficients $\alpha_{i}$,

$\alpha_{i} \cdot \Delta M_{\text {Terpene }}=M_{i}$ and $M_{i}=M_{i}^{l}+M_{i}^{g}$ and $Y \cdot \Delta M_{\text {Terpene }}=\sum M_{i}^{l}$ 


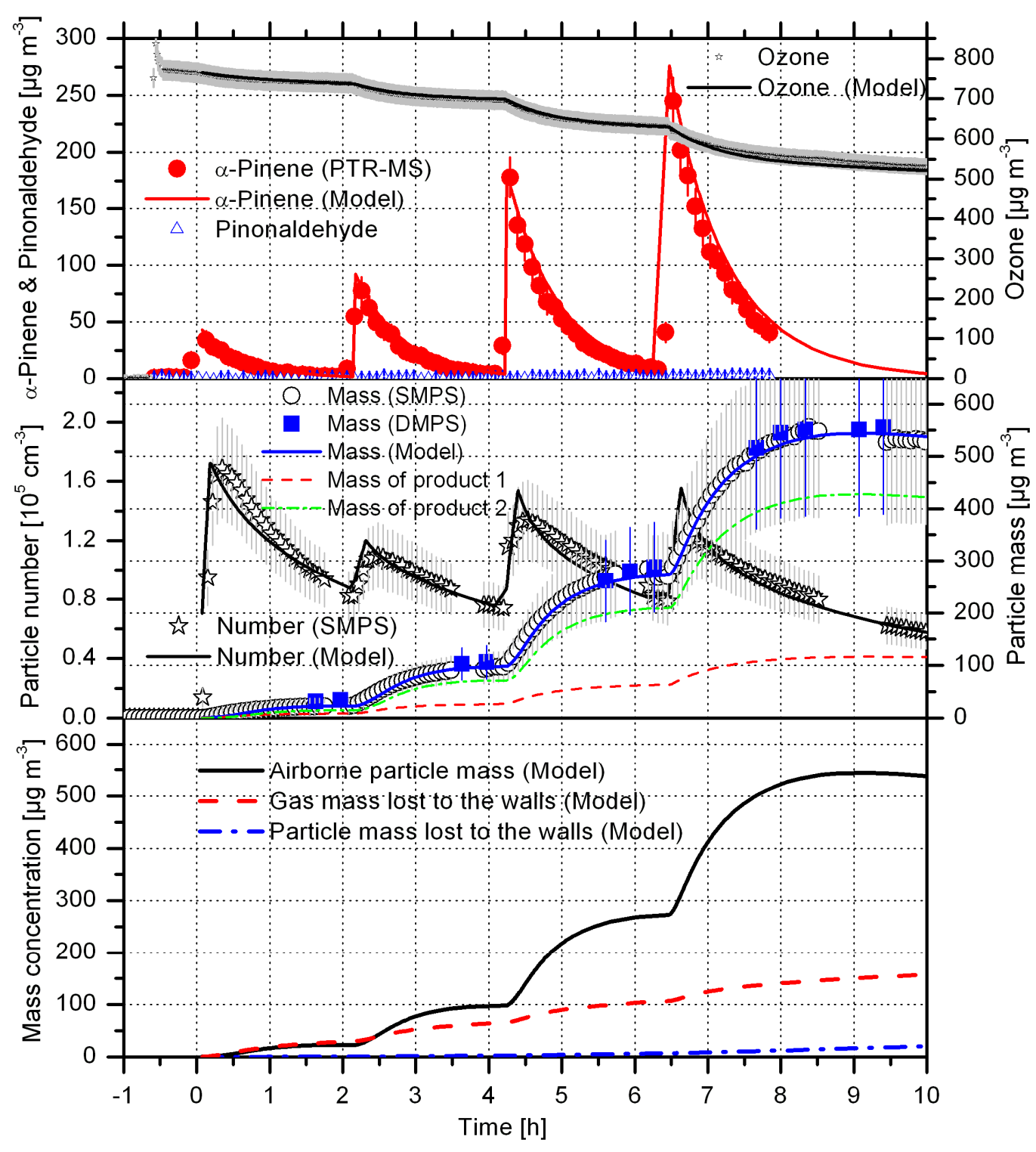

Fig. 2b. Evolution of measured trace gas, particle number, and mass concentrations (symbols) and model results including wall losses (lines) for experiment SOA05-10 at $243 \mathrm{~K}$.

where $M_{i}^{l}$ and $M_{i}^{g}$ denote the mass concentrations of component $i$ in the particle and in the gas phase, respectively. Assuming ideal mixing, the temperature dependence of $K_{i}$ can be represented by Eq. (3):

$K_{i}=\frac{M_{i}^{l}}{M_{i}^{g} \cdot M_{0}}=\frac{10^{-6} \cdot R \cdot T}{\left\langle M W_{O}\right\rangle \cdot p_{i}^{0}}=\frac{10^{-6} \cdot R \cdot T}{\left\langle M W_{O}\right\rangle \cdot B_{i}^{0}} \exp \left(\frac{\Delta H_{i}^{0}}{R T}\right)\left[m^{3} \mu g^{-1}\right]$

Here $R$ stands for the gas constant, $T$ for the absolute temperature, and $\left\langle M W_{O}>\right.$ for the average molar weight of the condensed matter. Further, $\mathrm{B}_{i}^{0}$ denotes the preexponential constant in the Clausius-Clapeyron type expression for $p_{i}^{0}$ and $\Delta \mathrm{H}_{i}^{0}$ is the enthalpy of vaporisation of component $i$. The description of $\alpha_{i}$ as function of $T$ requires detailed knowledge about the important temperature dependent steps in the degradation mechanism which are still uncertain. The analysis of the temperature dependence of these coefficients will therefore remain beyond the scope of this paper.

A potential drawback of the $K-\alpha$ approach associated with the neglect of non-equilibrium processes could arise from the size dependence of the vapour pressure of small particles due to the Kelvin effect. During the early stages of chamber experiments on SOA formation, for example, constant $K_{i}$ values will definitively prove inadequate to describe the observed aerosol dynamics except for cases where seed aerosol is used to suppress new particle formation. Furthermore, product vapour pressures determined by fitting Eqs. (1) and (2) to measured $Y$ vs. $M_{0}$ data series will show 
a tendency towards overestimation. However, chamber studies focussing merely on aerosol yield and mass concentration may not be severely affected by the Kelvin effect since the contribution of the small particle fraction to the overall mass of an aged aerosol is often negligible.

\section{Results and discussion}

All experiments with $\alpha$-pinene and limonene considered in this paper are listed in Tables A1 and A2, respectively. They include temperature, relative humidity, initial monoterpene concentrations, corresponding peak concentrations of the particle mass, as well as SOA yields obtained for each time interval following the addition of terpene. The yields presented in Tables A1 and A2 were calculated using the parameterisations derived from the COSIMA-assisted evaluation of the measurements as described in detail below. Because significant amounts of newly formed condensable oxidation products were lost directly from the gas phase to the walls of the AIDA chamber, an effect which cannot be corrected for by straightforward procedures, it proved impossible to conduct an analogous analysis within the framework of the $K-\alpha$ approach for comparison (cf. Sect. 4.1.1).

\subsection{SOA from $\alpha$-pinene ozonolysis}

The formation of SOA from the ozonolysis of $\alpha$-pinene was investigated in the temperature range $243-313 \mathrm{~K}$, for total organic aerosol mass concentrations ranging up to $820 \mu \mathrm{g} \mathrm{m}^{-3}$, for water mixing ratios ranging from a few ppm to several $10^{4} \mathrm{ppm}$, and with and without the radical scavengers cyclohexane and 2-butanol. The typical behaviour of the measured trace gas and particle concentrations is shown for one experiment at $303 \mathrm{~K}$ and for one at $243 \mathrm{~K}$ in Fig. 2 including a comparison with model results. The $\alpha$-pinene concentrations rapidly decrease after addition to the excess of ozone. Since the time resolution of the $\alpha$-pinene measurements is about 5 min the model fit to data is initialised with the absolute amount of $\alpha$-pinene added to the chamber. The kinetics of the $\alpha$-pinene+ozone reaction was reproduced without significant discrepancies by extrapolating the temperature dependence of rate coefficients from the literature (Atkinson et al., 1982; Atkinson, 1997). A more thorough analysis of the low temperature kinetics of the $\alpha$-pinene+ ozone reaction will be given elsewhere (Tillmann et al., 2008).

With respect to the particulate phase our analysis revealed that the assumption of only two effective reaction products (proxies) is sufficient to reproduce the experimental results well within their errors for all conditions considered in our study. In the following product 1 will represent a compound with low volatility which can act as a solvent for a semivolatile product 2 . For $\alpha$-pinene the aerosol mass concentrations were calculated from experimental size distributions using a SOA material density of $(1.25 \pm 0.1) \mathrm{g} \mathrm{cm}^{-3}$ as determined by comparing the size distributions measured with the AMS and SMPS instruments (c.f. Sect. 4.1.2.). The central plots in Fig. 2 show the observed and simulated time evolution of the particle number and mass concentrations as well as the predicted mass concentrations of the two effective SOA forming reaction products of the $\alpha$-pinene oxidation. In Fig. 3 measured size distributions (colour coded) are compared with modelled isolines of the corresponding number concentrations on a logarithmic scale. At $303 \mathrm{~K}$ nucleation only occurred after the first addition of the $\alpha$-pinene to an excess of ozone. At lower temperatures new particles were also formed in subsequent additions. However, the dominant mass fraction always resulted from condensation onto SOA particles which had been formed after the first addition of $\alpha$-pinene.

At and above $303 \mathrm{~K}$ the initial growth rate of the SOA mass is comparable to the decay rate of the $\alpha$-pinene mass. Hence, the ozonolysis is the rate limiting step for the SOA formation under these conditions. With decreasing temperature, however, the initial rate of SOA mass formation gradually slows down compared to the decay of the precursor mass concentration. At $243 \mathrm{~K}$ the degradation of $\alpha$-pinene proceeds approximately two times faster than the creation of condensed material. Although diffusion of condensable species from the gas phase to the surface of the particles becomes slower with decreasing temperature, the model analysis indicates that this effect cannot explain the observed retardation of SOA formation. More likely intermediate reaction products become more stable at lower temperatures, thus retarding the formation of condensable compounds. Furthermore, the predominant reaction pathways contributing to the SOA yield may differ from the kinetics at elevated temperatures. Since COSIMA-SOA does not contain a detailed chemistry module, the easiest way to account for this effect is to artificially decrease the effective accommodation coefficients $\gamma_{i}$, thereby formally transforming the chemical delay into a pseudo transport limitation. As a consequence of this measure the $\gamma_{i}$ are decreasing with decreasing temperature in contrast to most observations and should not be regarded as physically meaningful parameters (cf. Sect. 4.1.3). Please note, however, that the observed delay in SOA formation compared to the depletion of the precursor under cold conditions could prove a serious obstacle regarding the unambiguous interpretation of online measurements of $\mathrm{dM} \mathrm{MSA}_{\mathrm{SO}} / \mathrm{dM}_{\text {Terpene }}$ with respect to low temperature yields.

\subsubsection{Wall losses in the simulation chamber}

In the course of the experiments trace gases and particles are inevitably lost to the aluminium walls of the AIDA simulation chamber. This sink must be carefully accounted for to allow a quantitative determination of SOA yields (Kroll et al., 2007). The formalism implemented into COSIMA to calculate size and temperature dependent diffusional and sedimentational particle wall loss rates is presented elsewhere 


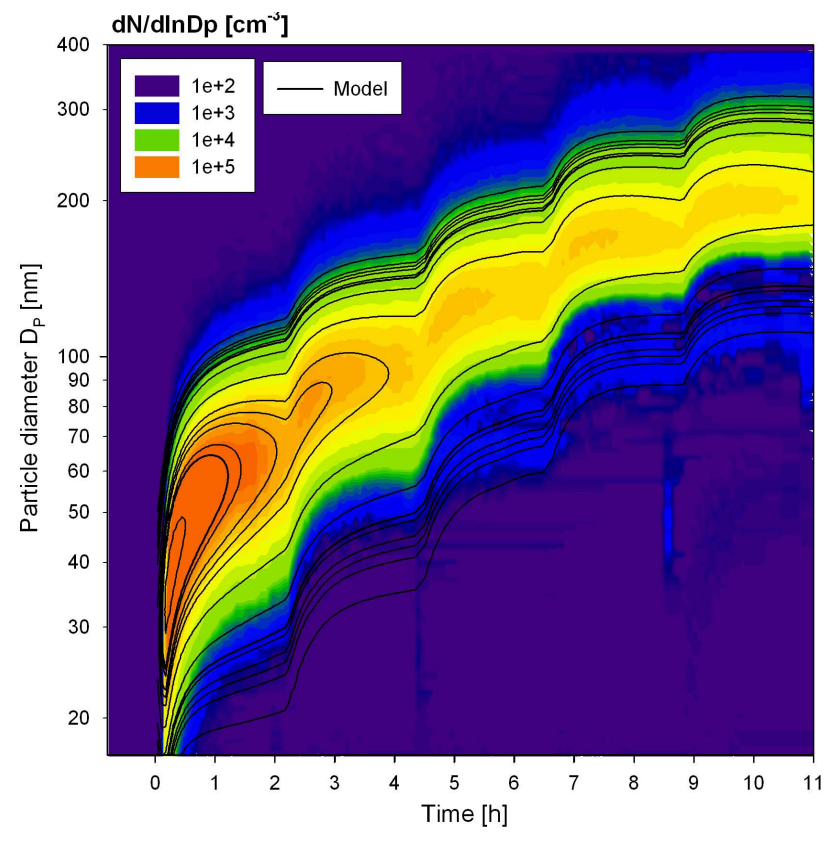

Fig. 3a. Evolution of the measured (colour code) and modelled (lines) particle size distribution for experiment SOA05-2 at $303 \mathrm{~K}$.

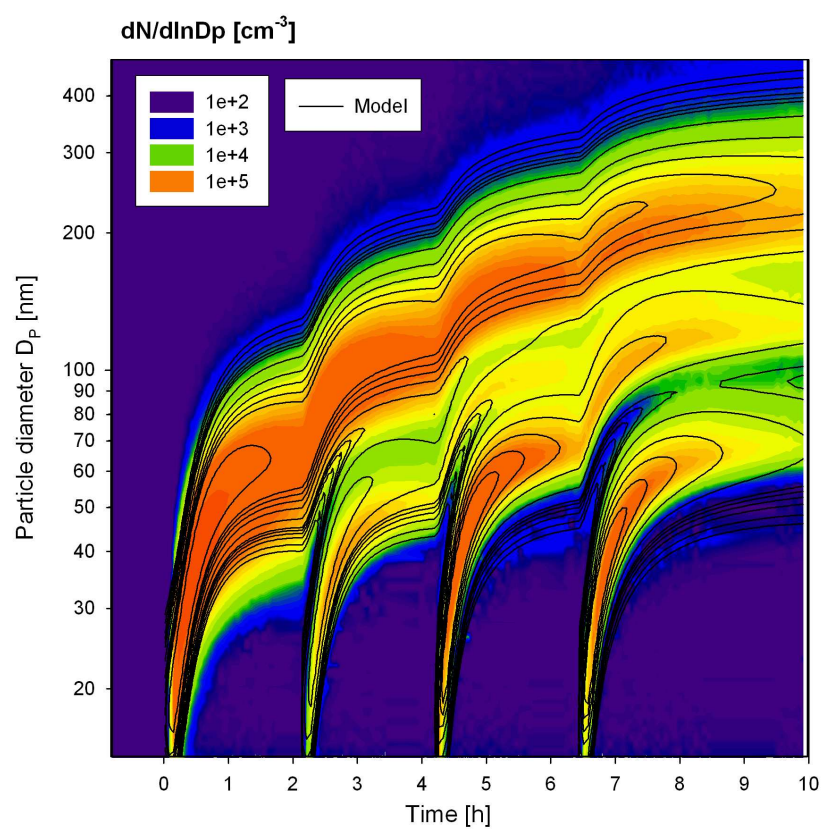

Fig. 3b. Evolution of the measured (colour code) and modelled (lines) particle size distribution for experiment SOA05-10 at $243 \mathrm{~K}$.

(Naumann, 2003). It has been extensively validated against experimental results for compact and fractal-like particles (Bunz and Dlugi, 1991; Naumann, 2003; Wentzel et al., 2003). Ozone wall loss rates are most reliably determined by inspecting the decrease of the $\mathrm{O}_{3}$ concentration in the absence of other reactants. However, in order to match the measured time evolution of the $\mathrm{O}_{3}$ concentration as close as possible, first order loss rate constants were fitted individually for each time interval initiated by adding $\alpha$-pinene or ozone into the chamber. The initial wall loss rate constant for ozone decreased from $(3.9 \pm 2.1) \times 10^{-5} \mathrm{~s}^{-1}$ at $303 \mathrm{~K}$ (average over seven experiments) to $(5.2 \pm 3.2) \times 10^{-6} \mathrm{~s}^{-1}$ at $243 \mathrm{~K}$ (average over four experiments). During one experiment the value always decreased due to the passivation of the chamber walls for ozone loss. The observed minimum was $(2.4 \pm 1.3) \times 10^{-5} \mathrm{~s}^{-1}$ at $303 \mathrm{~K}$ (average over seven experiments) and ranged from effectively zero to $2.0 \times 10^{-6} \mathrm{~s}^{-1}$ at $243 \mathrm{~K}$. Generally, there is a tendency towards reduced $\mathrm{O}_{3}$ wall losses for dry conditions compared to humid ones.

In comparison to the ozone case, quantifying the losses of the low and semivolatile oxidation products of $\alpha$-pinene from the gas phase to the chamber wall is more complex. By adding the organic precursor to an excess of ozone, supersaturation of condensable species is rapidly established in the gas phase, leading to a fast partitioning into the particulate phase as manifested by the corresponding increase in SOA mass concentration (cf. Fig. 2). However, irreversible wall losses of semivolatile and, to a smaller extent, low volatile oxidation products always counteract the condensation process, eventually leading to evaporation of SOA material once the precursor has been sufficiently depleted. The corresponding decay of SOA mass concentration is most pronounced during time intervals initiated by adding large amounts of $\alpha$ pinene into the chamber. The calculated decay of airborne mass and the related decrease in particle size proved to be quite sensitive to the wall loss rate coefficient of product 2 . The values thus determined for $\mathrm{k}_{2}$ ranged from $1.0 \times 10^{-4} \mathrm{~s}^{-1}$ to $7.0 \times 10^{-4} \mathrm{~s}^{-1}$ for different experiments. Due to the much lower vapour pressure of product 1 the effect of $k_{1}$ on the time evolution of mass concentration and particle size is less pronounced, especially at low temperatures. The model analysis revealed, however, that the simulated evaporational loss rate of small particles and thus the calculated number concentration also responds to significant changes of $k_{1}$. Therefore, by considering mass and number concentrations as well as size distributions simultaneously it proved possible to obtain reasonable estimates for $k_{1}$ ranging from $1 \times 10^{-4} \mathrm{~s}^{-1}$ to $3 \times 10^{-4} \mathrm{~s}^{-1}$. It should be noted that neither $k_{1}$ nor $\mathrm{k}_{2}$ showed a significant dependence on temperature.

The findings outlined above indicate that considerable amounts of condensable material are lost from the gas phase to the chamber wall in the course of an experiment. The bottom graphs in Fig. 2 display the computed time evolution of the SOA mass concentration together with those of the integrated wall losses from gas and particulate phase, respectively, the latter being converted to units of mass per volume in order to facilitate the comparison. At $303 \mathrm{~K}$ the amount of material lost from the gas phase is of the same order of magnitude as the observed SOA concentration. The associated loss term is clearly dominated by the semivolatile product 2 , reflecting both its higher vapour pressure and its 
larger yield coefficient. Modelling the $243 \mathrm{~K}$ scenario the simulation predicts - except for the time interval following the first addition of $\alpha$-pinene - a much smaller relative loss of condensable products from the gas phase to the wall which, however, still comprises a significant part of the total product yield. Again, the major portion of the gas phase wall loss is attributed to product 2. Please note, that for both cases illustrated in Fig. 2 the total of condensable gaseous species lost to the chamber wall remains well below the equivalent of one monolayer (estimated to about $200 \mu \mathrm{g} \mathrm{m}^{-3}$ based on the molecular size parameters reported by Bilde and Pandis (2001) and assuming a perfectly flat wall surface). The same applies to all experiments considered in this paper. Furthermore, modelling experiments SOA05-1 and SOA05-13 conducted at $303 \mathrm{~K}$ where the time evolutions of size distribution and mass concentration have been monitored for more than $17 \mathrm{~h}$ after the last injection of $\alpha$-pinene the observations could be consistently reproduced allowing complete evaporation of product 2 from the particle phase. Thus, the assumption of irreversible wall losses appears to be reasonable. For all experiments the calculated loss of particulate mass to the chamber walls turns out to be comparatively small. The contribution of this loss term to the mass balance is always much less than the uncertainty of the experimental airborne mass concentration as determined from the SMPS measurements. For a given amount of precursor it increases on an absolute scale with decreasing temperature due to the higher mass yields and the formation of larger particles. Regarding the cases considered in Fig. 2 the diffusional and sedimentational particle wall loss rates increase roughly three and six times, respectively, going from $303 \mathrm{~K}$ to $243 \mathrm{~K}$.

Due to the large wall loss rate coefficients of the gaseous oxidation products in the AIDA chamber the transport rates of condensable matter from the gas phase to the particle surface and to the wall become comparable by order of magnitude. As a result, newly formed condensable material may be lost directly to the wall without ever having partitioned into the SOA phase. Consequently, it proves very difficult to correct the SOA yields determined by analysing the time evolution of the particulate mass concentration for wall losses and evaporation effects in a straightforward manner. Pathak et al. (2007b) fitted a first order expression to the observed time evolution of the aerosol mass $M(t)$ using measurements where more than $90 \%$ of the initial $\alpha$-pinene had reacted. The produced SOA was then calculated according to

$\operatorname{SOA}(t)=M(t)+k \int_{0}^{t} M(t) d t-M_{S}$

with $k$ representing the first order loss rate constant and $M_{S}$ the mass of pre-existing aerosol at time $t=0$, respectively. Other studies applied bi-exponential fits to the measured $M(t)$-data, thereby representing both SOA formation and SOA losses by first order rate laws. These procedures rely on the assumption that only losses from the particulate phase need to be accounted for. However, for the AIDA experi- ments presented in this paper the presupposition of negligible gas phase wall losses of low and semi-volatile organic species is definitely not fulfilled. The same could be true for other chambers as well. Please note, however, that the aerosol mass wall losses reported by Pathak et al. (2007b) $\left(10 \mathrm{~m}^{3}\right.$ Teflon reactor, $k=0.07$ to $\left.0.48 \mathrm{~h}^{-1}\right)$ are roughly 20 to 200 times higher than in AIDA at comparable temperatures. If wall losses of condensable products from the gas phase are much smaller in Teflon bags compared to our estimates then particle removal could indeed be the most relevant loss process in SOA work conducted similarly to the experiments described by Pathak et al. (2007b). In our case, the detailed process model analysis of SOA experiments, although much more complex due to the simultaneous consideration of trace gas and particle wall loss effects on size distribution as well as mass and number concentration, allows accounting for all relevant loss processes without suffering from the limitations mentioned above. Consequently, knowing the gas phase and particle wall losses as function of time, the evolution of the total SOA yield is then readily evaluated.

\subsubsection{Density of the organic aerosol from $\alpha$-pinene ozonolysis}

Effective densities of the SOA were derived from comparisons of the mass distribution and volume distribution of the aerosol measured with an aerosol mass spectrometer (AMS) and an SMPS, respectively. While the AMS measures mass distribution versus vacuum aerodynamic diameter, the SMPS measures size distribution versus mobility diameter. The SMPS size distribution can be converted into a volume distribution versus mobility diameter. The two diameters are related via:

$\rho_{\mathrm{eff}}=\frac{d_{v a}}{d_{m}} \rho_{0}$

where $\rho_{\text {eff }}$ is the effective density, $d_{v a}$ the vacuum aerodynamic diameter, $d_{m}$ the mobility equivalent diameter and $\rho_{0}$ is unit density (DeCarlo et al., 2004). When determining the effective density the following approach was used. Each volume and mass distribution was fitted with a log normal distribution. An interpolation was used to account for the different time resolutions of the two instruments. The mode diameters of the fitted distributions were taken as $d_{v a}$ and $d_{m}$, respectively, to determine $\rho_{\text {eff }}$ from Eq. (5). The method has been proven successful to better than $\pm 10 \%$ (Bahreini et al., 2005). Figure 4 shows the effective densities of SOA formed by ozonolysis of $\alpha$-pinene during four different experiments performed at different temperatures and at humid conditions. In the humid experiments no temperature dependence of the effective SOA density can be observed. All densities agree within the errors and show an average SOA density of $(1.25 \pm 0.10) \mathrm{g} \mathrm{cm}^{-3}$. This value is somewhat higher than the density of $(1.04 \pm 0.09) \mathrm{g} \mathrm{cm}^{-3}$ (Wirtz and Martin-Reviejo, 2003) determined by combining SMPS and microbalance 
Table 1. Mass stoichiometric yield parameters $\left(\alpha_{i}\right)$, vapour pressures $\left(p_{i}\right)$, partitioning coefficients $\left(K_{i}\right)$, and effective accommodation coefficients $\left(\gamma_{i}\right)$ determined for two effective SOA forming products of the $\alpha$-pinene ozonolysis.

\begin{tabular}{ccccccccccc}
\hline Experiment & $\begin{array}{c}T \\
{[\mathrm{~K}]}\end{array}$ & $\begin{array}{c}\mathrm{RH} \\
{[\%]}\end{array}$ & $\alpha_{1}$ & $\alpha_{2}$ & $\begin{array}{c}p_{1} \\
{[\mathrm{bar}]}\end{array}$ & $\begin{array}{c}p_{2} \\
{[\mathrm{bar}]}\end{array}$ & $\begin{array}{c}K_{1} \\
{\left[\mathrm{~m}^{3} \mu \mathrm{g}^{-1}\right]}\end{array}$ & $\begin{array}{c}K_{2} \\
{\left[\mathrm{~m}^{3} \mu \mathrm{g}^{-1}\right]}\end{array}$ & $\gamma_{1}^{\mathrm{c}}$ & $\gamma_{2}^{\mathrm{c}}$ \\
\hline SOA03-5 & 313.2 & 16 & 0.057 & 0.185 & $1.5 \mathrm{E}-10$ & $8.5 \mathrm{E}-09$ & 1.0 & 0.018 & 0.160 & 1.000 \\
SOA03-4 & 303.3 & 38 & 0.089 & 0.185 & $1.1 \mathrm{E}-10$ & $7.0 \mathrm{E}-09$ & 1.3 & 0.021 & 0.220 & 1.000 \\
SOA05-1 & 303.2 & 46 & 0.121 & 0.169 & $1.0 \mathrm{E}-10$ & $7.0 \mathrm{E}-09$ & 1.4 & 0.021 & 0.200 & 1.000 \\
SOA05-2 & 303.3 & 0.02 & 0.106 & 0.235 & $8.0 \mathrm{E}-11$ & $7.0 \mathrm{E}-09$ & 1.8 & 0.021 & 0.200 & 1.000 \\
SOA05-12 & 303.2 & 44 & 0.205 & 0.321 & $7.5 \mathrm{E}-11$ & $7.0 \mathrm{E}-09$ & 1.9 & 0.021 & 0.300 & 1.000 \\
SOA05-13 & 303.2 & 44 & 0.168 & 0.222 & $9.0 \mathrm{E}-11$ & $7.0 \mathrm{E}-09$ & 1.6 & 0.021 & 0.200 & 1.000 \\
SOA06-1 & 303.0 & 46 & 0.12 & 0.184 & $1.1 \mathrm{E}-10$ & $7.0 \mathrm{E}-09$ & 1.4 & 0.021 & 0.200 & 1.000 \\
SOA06-3 & 303.2 & 45 & 0.122 & 0.272 & $9.0 \mathrm{E}-11$ & $7.0 \mathrm{E}-09$ & 1.6 & 0.021 & 0.200 & 1.000 \\
SOA03-3 & 293.3 & 35 & 0.115 & 0.274 & $6.0 \mathrm{E}-11$ & $5.0 \mathrm{E}-09$ & 2.3 & 0.028 & 0.300 & 0.850 \\
SOA03-2 & 283.4 & 31 & 0.127 & 0.358 & $(8.0 \mathrm{E}-11)$ & $3.4 \mathrm{E}-09$ & $(1.7)$ & 0.040 & 0.300 & 0.550 \\
SOA03-1 & 273.6 & 30 & 0.191 & 0.364 & $(1.2 \mathrm{E}-10)$ & $2.4 \mathrm{E}-09$ & $(1.1)$ & 0.055 & 0.200 & 0.300 \\
SOA06-6 & 273.0 & 73 & 0.205 & 0.593 & $7.0 \mathrm{E}-12$ & $2.4 \mathrm{E}-09$ & 18.8 & 0.055 & 0.190 & 0.300 \\
SOA03-6 & 253.2 & 70 & 0.198 & 0.877 & $1.0 \mathrm{E}-12$ & $7.0 \mathrm{E}-10$ & 123.1 & 0.176 & 0.100 & 0.012 \\
SOA05-8 & 253.0 & 68 & 0.198 & 0.976 & $8.3 \mathrm{E}-13$ & $1.0 \mathrm{E}-09$ & 148.4 & 0.123 & 0.100 & 0.012 \\
SOA05-7 & 252.9 & 0.17 & 0.198 & 0.791 & $8.3 \mathrm{E}-13$ & $1.0 \mathrm{E}-09$ & 147.9 & 0.123 & 0.100 & 0.007 \\
SOA05-9 & 243.1 & 71 & 0.219 & 1.04 & $2.5 \mathrm{E}-13$ & $7.0 \mathrm{E}-10$ & 473.1 & 0.169 & 0.100 & 0.030 \\
SOA05-10 & 243.1 & 7.5 & 0.219 & 1.04 & $2.5 \mathrm{E}-13$ & $7.0 \mathrm{E}-10$ & 473.1 & 0.169 & 0.100 & 0.010 \\
\hline
\end{tabular}

${ }^{a}$ No OH scavenger added. ${ }^{b}$ 2-Butanol used as $\mathrm{OH}$ scavenger. ${ }^{\mathrm{c}}$ values strongly influenced by changes in chemical reaction mechanism. Values in brackets could not be determined unambiguously.

(TEOM) data at $299 \mathrm{~K}$. It agrees well with densities obtained in other experiments combining AMS and SMPS data, $1.19 \mathrm{~g} \mathrm{~cm}^{-3}$ (Bahreini et al., 2005), $1.30 \mathrm{~g} \mathrm{~cm}^{-3}$ (Alfarra et al., 2006), and $1.23 \mathrm{~g} \mathrm{~cm}^{-3}$ reported by Shilling et al. (2008) for SOA mass concentrations above about $15 \mu \mathrm{g} \mathrm{m}^{-3}$ but it is lower than the value of $\sim 1.5 \mathrm{~g} \mathrm{~cm}^{-3}$ given by Kostenidou et al. (2007) that was also obtained from SMPS-AMS at $293 \mathrm{~K}$. Under dry conditions a larger variability of the effective densities was observed. Possibly this could be due to shape factors being in effect in the absence of water. However, shape factors significantly different from unity are not supported by the model analysis of the aerosol dynamics. Since no independent determination of the shape factor was possible in these experiments, the same average density of $(1.25 \pm 0.10) \mathrm{g} \mathrm{cm}^{-3}$ was applied for the dry experiments as for the humid experiments. No significant change with time in the effective density of the SOA was observed for experiments conducted during $24 \mathrm{~h}$ (SOA05-1).

\subsubsection{Parameters of the two effective SOA forming products (proxies)}

In the following the parameterisation optimised to reproduce the experimental results within the framework of a two product model approach will be presented and discussed. The results of the COSIMA-assisted analysis regarding the mass stoichiometric yield coefficients $\alpha_{i}$, the partitioning coefficients $K_{i}$, the bulk vapour pressures $p_{i}^{0}$, and the effective accommodation coefficients $\gamma_{i}$ are summarised in Table 1. Some experiments listed in Table A1 were omitted in Table 1 because the database was insufficient for an independent detailed model analysis. For example, the evaluation of single step experiments at low SOA mass concentrations often suffered from ambiguous quantification of the wall losses of condensable species. Not all parameters could be determined by fitting simulated time evolutions of particle size distribution, mass and number concentration to measured ones. The molar masses $M W_{i}$, the surface tensions $\sigma_{i}$, and the gas phase diffusivities $\mathrm{D}_{i}$ of the condensable product species had to be specified beforehand as outlined below. 
For all experiments molar masses for products 1 and 2 were taken as $186 \mathrm{~g} \mathrm{~mol}^{-1}$ and $168 \mathrm{~g} \mathrm{~mol}^{-1}$, respectively. These values correspond to typical monomeric oxidation products of $\alpha$-pinene like pinic acid and pinonaldehyde, respectively (Yu et al., 1999a; Jenkin, 2004). Using higher values as typical for dimers or trimers would result in reduced molecular transport rates from the gas phase to the particle surface. However, the SOA yields predicted by COSIMA depend only weakly on the choice of these parameters. Applying higher molar masses would lead to reduced molar yields in order to retain the mass yield factors $\alpha_{i}$. These were fixed independently by matching the calculated aerosol particle mass concentrations $\mathrm{c}_{M}(\mathrm{t})$ to the respective observed ones.

The surface tensions of the two product proxies determine the magnitude of the Kelvin effect which mainly affects the evaporation rates of small particles and therefore manifests itself in the time evolution of the particle number concentration $c_{N}$. A parameter analysis revealed that $c_{N}$ is both sensitive to variations of bulk vapour pressures $p_{i}^{0}$ and surface tensions $\sigma_{i}$. However, similar to the experiences reported by Bilde and Pandis (2001) we could not obtain reasonable results for the temperature dependence of $\sigma_{1}$ and $\sigma_{2}$ by fitting them to our experimental data simultaneously with the vapour pressures. Therefore we decided to conduct our simulations assuming constant surface tensions. For pinic acid a surface tension has been estimated theoretically to $34.22 \mathrm{dyn} \mathrm{cm}^{-1}$ (Cai and Griffin, 2005) and to $(110 \pm 90) \mathrm{dyn} \mathrm{cm}^{-1}$ (Koch et al., 2000) from experimental data. Since product 1 exhibits a much lower vapour pressure than pinic acid (as will be discussed below), we consider it reasonable to apply an accordingly adjusted value for $\sigma_{1}$. The value of $\sigma_{1}=80 \mathrm{dyn} \mathrm{cm}^{-1}$ adopted in our model runs resulted in good agreement between measured and calculated aerosol properties. The value of $30 \mathrm{dyn} \mathrm{cm}^{-1}$ used for product 2 lies well within the range of $20-40 \mathrm{dyn}^{-1}$ typically observed for pure saturated organic liquids (Bilde and Pandis, 2001). For the gas phase diffusion coefficients of products 1 and 2 values increasing from $0.040 \mathrm{~cm}^{2} \mathrm{~s}^{-1}$ at $243 \mathrm{~K}$ to $0.056 \mathrm{~cm}^{2} \mathrm{~s}^{-1}$ at $313 \mathrm{~K}$ were calculated from the LennardJones parameters provided by Bilde and Pandis (2001) using the correlation given in Poling et al. (2000).

The choice of the effective accommodation coefficients $\gamma_{i}$ significantly affects particle growth kinetics and thus the predicted time evolutions of aerosol particle mass concentration and size distribution. Simulating their outdoor smog chamber experiments on the photooxidation of $\mathrm{m}$-xylene in the presence of $\mathrm{NO}_{\mathrm{x}}$, Bowman et al. (1997) estimated $\gamma$ to have a value between 0.1 and 1 , with $\gamma=0.2$ resulting in a good fit to their experimental observations. This value has subsequently been adopted in other studies, but many workers still prefer the limiting value 1.0. Considering product 1 , we find good agreement between measurements and simulations using $\gamma_{1}=0.19-0.30$ for temperatures $T \geq 283 \mathrm{~K}$ (cf. Fig. 3b) in accordance with Bowman et al. (1997) while

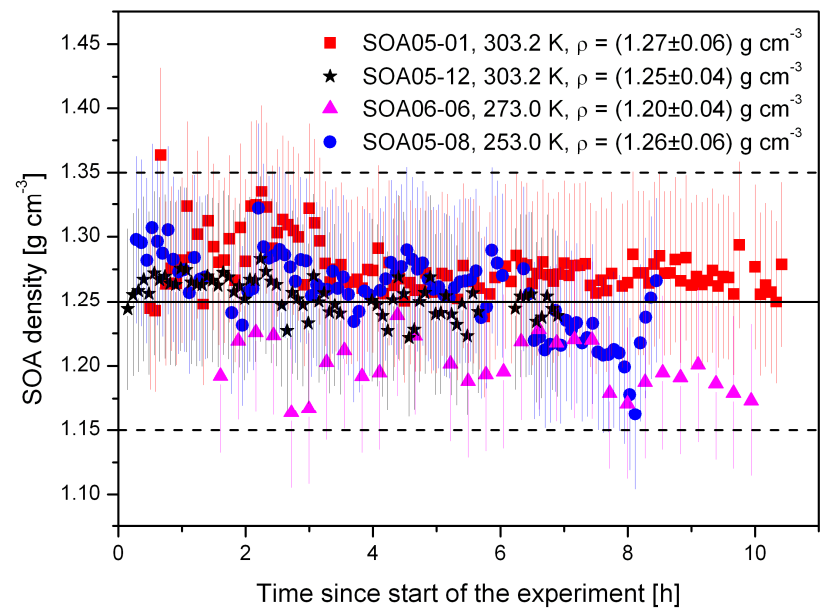

Fig. 4. Effective density of SOA from $\alpha$-pinene ozonolysis as determined by combining AMS and SMPS data for four different experiments.

significantly larger $\gamma_{1}$ values resulted in overestimating the particle growth rate. Regarding product 2, optimum simulation results were obtained with $\gamma_{2}=1.0$ for $T \geq 303 \mathrm{~K}$. For temperatures around and below $253 \mathrm{~K}$ it proved necessary to reduce $\gamma_{1}$ to 0.1 . A much more pronounced temperature dependence was found for $\gamma_{2}$ which decreased to $0.01-0.03$ for $T=243 \mathrm{~K}$. Of course, from a purely physical point of view one would expect accommodation coefficients to increase with decreasing temperature. Here, however, the observed temperature dependencies of $\gamma_{1}$ and $\gamma_{2}$ are mainly reflecting the chemically induced low temperature retardation of SOA formation in relation to the consumption of $\alpha$-pinene as already outlined in Sect. 4.1. Therefore, in the context of this paper $\gamma_{1}$ and $\gamma_{2}$ have to be considered as effective quantities without well defined physical meaning. The temperature dependent effective accommodation coefficients listed in Table 1 should thus be useful with model approaches that do not attempt to consider resistances in the SOA formation channels within a more or less detailed chemical reaction scheme beyond the primary terpene oxidation step.

Figure 5 shows the temperature dependences of the vapour pressures $\left(p_{1} ; p_{2}\right)$ of the two effective SOA forming ozonolysis products (proxies) of $\alpha$-pinene. Figure 6 shows the mass stoichiometric yields of the two effective SOA forming products $\left(\alpha_{1} ; \alpha_{2}\right)$ and the partitioning coefficients $\left(K_{1} ; K_{2}\right)$ as a function of temperature. Please note that $K_{1}$ and $K_{2}$, calculated from $p_{1}$ and $p_{2}$ in the limit of large $M_{o}$ where $<\mathrm{MW}_{o}>$ approaches a constant value, are provided here in order to facilitate the comparison of our results with literature data. Since the concept of partitioning coefficients is only meaningful for equilibrated systems it is not used within the framework of the COSIMA model. The mass stoichiometric yield coefficient $\alpha_{2}$ is increasing from about 0.2 above $300 \mathrm{~K}$ and approaching unity around $250 \mathrm{~K} . \alpha_{2}$ shows much stronger 


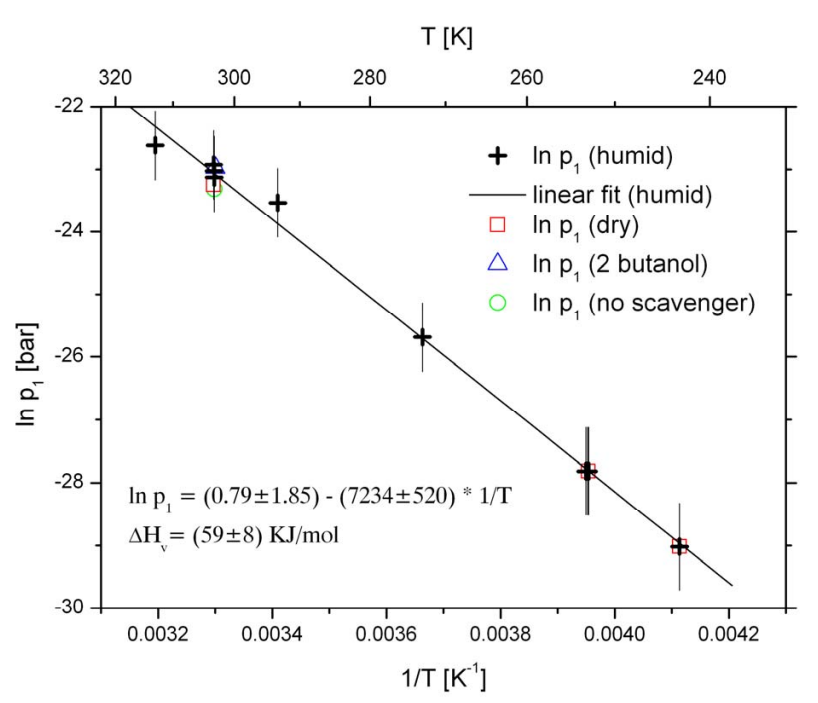

Fig. 5a. Temperature dependence of the vapour pressure of the less volatile SOA forming product 1 of the ozonolysis of $\alpha$-pinene.

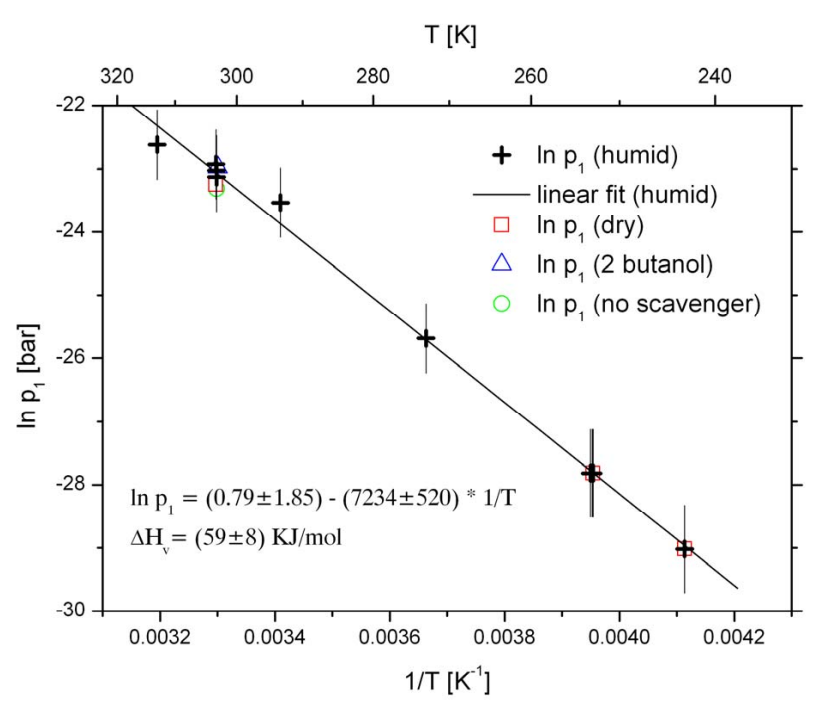

Fig. 5b. Temperature dependence of the vapour pressure of the more volatile SOA forming product 2 of the ozonolysis of $\alpha$-pinene.

temperature dependence than $\alpha_{1}$ and a different functional dependence. The temperature dependence for $\alpha_{1}$ can be approximated with a linear fit while for $\alpha_{2}$ an almost exponential behaviour can be fitted. The physical meaning behind this is however not established. The following parameterisations of the mass stoichiometric yield coefficients $\left(\alpha_{i}\right)$ were derived from the individual experiments for the temperature range between 243 and $313 \mathrm{~K}$ and for humid conditions:

$\alpha_{1}=(0.715 \pm 0.138)-(0.0020 \pm 0.0005) * T$

$\alpha_{2}=(1200 \pm 400) * \exp (-T /(35 \pm 2))$

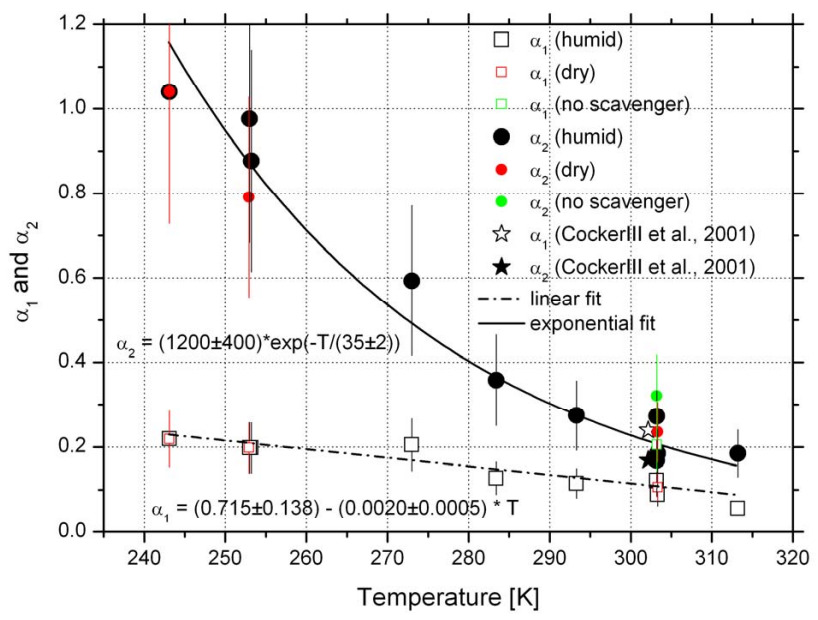

Fig. 6a. Temperature dependence of the mass stoichiometric yield coefficients of the two effective SOA forming reaction products of the ozonolysis of $\alpha$-pinene.

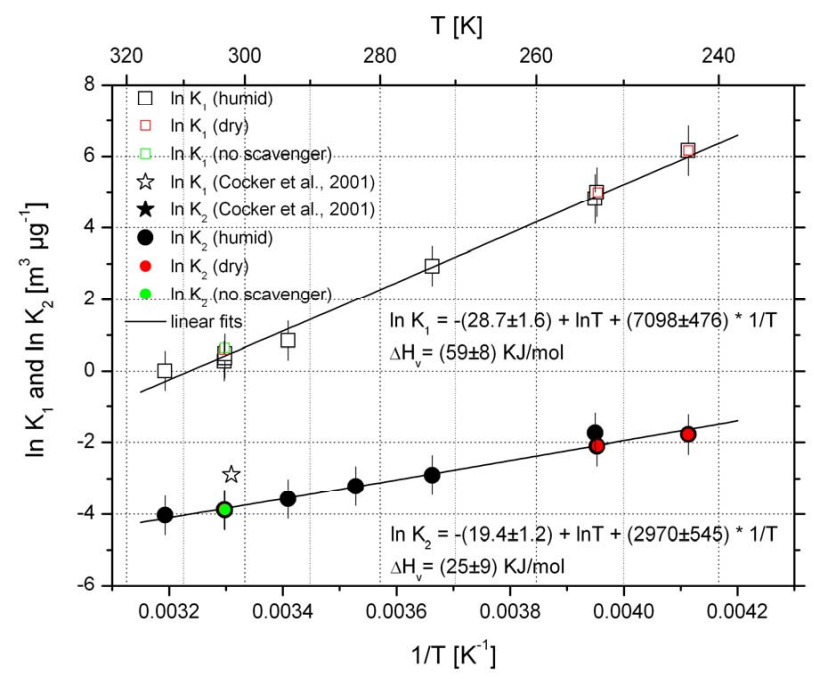

Fig. 6b. Temperature dependence of the partitioning coefficients of the two effective SOA forming reaction products of the ozonolysis of $\alpha$-pinene.

The sum of $\alpha_{1}$ and $\alpha_{2}$ may approach a maximum value of 1.25 at $243 \mathrm{~K}$ if we assume an average molar mass for the SOA of $171 \mathrm{~g} \mathrm{~mol}^{-1}$, i.e. a SOA composition of $17 \%$ product 1 with $186 \mathrm{~g} \mathrm{~mol}^{-1}$ and of $83 \%$ product 2 with $168 \mathrm{~g} \mathrm{~mol}^{-1}$. Please note that at $243 \mathrm{~K}$ the SOA yield is at its theoretical limit and the exponential fit exceeds this limit by about $10 \%$. However, considering estimated uncertainties of about $\pm 30 \%$ for the mass stoichiometric yield coefficients a further interpretation is not reasonable. The value obtained in this work for $\alpha_{1}=0.11$ at $302 \mathrm{~K}$ is significantly lower than the value of $\alpha_{1}=0.239$ reported by Cocker et al. (2001) but their value of $\alpha_{2}=0.169$ agrees within the uncertainties with 
our value of $\alpha_{2}=0.22$. Empirical fitting to a range of measured data led to values of $\alpha_{1}=0.08$ and $\alpha_{2}=0.42$ for $310 \mathrm{~K}$ (Svendby et al., 2008). Figures 5 and $6 \mathrm{~b}$ show that the temperature dependence of the vapour pressures and the corresponding partitioning coefficients follows typical Clausius Clapeyron behaviour. The following parameterisations of the vapour pressures $\left(p_{i}\right)$ were derived from the individual experiments for the temperature range $243-313 \mathrm{~K}$ and for humid conditions:

$$
\begin{aligned}
& \ln p_{1}[\mathrm{bar}]=(0.79 \pm 1.85)-(7234 \pm 520) / \mathrm{T} \\
& \ln p_{2}[\mathrm{bar}]=-(9.32 \pm 1.90)-(2875 \pm 533) / \mathrm{T}
\end{aligned}
$$

The partitioning coefficients of ideal mixtures are directly related to the vapour pressures via Raoult's law (see Eq. 3). This is confirmed by the close agreement between the corresponding slopes in Figs. 5 and $6 \mathrm{~b}$, but with opposite signs. The corresponding parameterisations of the partitioning coefficients $\left(K_{i}\right)$ for the temperature range between 243 and $313 \mathrm{~K}$ and for humid conditions assuming negligible Kelvin effect are as follows:

$$
\begin{aligned}
& \ln K_{1}\left[m^{3} \mu g^{-1}\right]=-(28.7 \pm 1.6)+\ln \mathrm{T}+(7098 \pm 476) / T(10) \\
& \ln K_{2}\left[m^{3} \mu g^{-1}\right]=-(19.4 \pm 1.2)+\ln \mathrm{T}+(2970 \pm 545) / T(11)
\end{aligned}
$$

The uncertainties estimated for $p_{1}$ and $K_{1}$ are $\pm 50 \%$ for $313-273 \mathrm{~K}$ and $\pm 100 \%$ for temperatures below this range. The uncertainties estimated for $p_{2}$ and $K_{2}$ are $\pm 50 \%$ for $313-243 \mathrm{~K}$. The values calculated in this work for $K_{1}=1.67$ and $K_{2}=0.021$ at $302 \mathrm{~K}$ are significantly higher than the values of $K_{1}=0.056$ and $K_{2}=0.0019$ reported by Cocker et al. (2001). Empirical fitting to a range of measured data led to values of $K_{1}=0.5$ and $K_{2}=0.005$ for $310 \mathrm{~K}$ (Svendby et al., 2008) which are closer to the results from this work but still significantly lower. However, please note that such a direct comparison could prove inconclusive e.g. due to the explicit consideration of the Kelvin effect and non-equilibrium behaviour in our analysis. Besides, there may be additional causes for these differences that cannot be identified in a straightforward manner.

The vapour pressures extracted in the temperature range $243-313 \mathrm{~K}$ for the less and more volatile component range from $2.5 \times 10^{-14}$ to $1.5 \times 10^{-10}$ and $7 \times 10^{-10}$ to $8.5 \times 10^{-9}$ bar, respectively. At $303 \mathrm{~K}$ the vapour pressures of the less and more volatile SOA forming compounds are within the same order of magnitude and comparable to vapour pressures at $296 \mathrm{~K}$ of pinic acid $\left(3.2 \times 10^{-10}\right.$ bar $)$, cis-pinonic acid $\left(7 \times 10^{-10}\right.$ bar $)$ and trans-norpinic acid $\left(1.3 \times 10^{-9}\right.$ bar $)$ (Bilde and Pandis, 2001), but well below the vapour pressures of the semivolatile compound pinonaldehyde. The vapour pressure of pinonaldehyde was measured to be $5.1 \times 10^{-5}$ bar at $298 \mathrm{~K}$ and $7 \times 10^{-6}$ bar at $243 \mathrm{~K}$ (Hallquist et al., 1997) but a recent analysis resulted in lower values of $10^{-7}$ to $10^{-9}$ bar at $303 \mathrm{~K}$ (Tillmann et al., 2009). Consequently, either of the two effective SOA forming products may represent the product class of acid or diacid products while it is unrealistic to compare with the much more volatile compounds with only carbonyl functional groups (Capouet and Müller, 2006). However, this is rather speculative, especially since several more oxidised or dimeric/oligomeric compounds have been proposed to be involved in SOA formation (Kalberer et al., 2004; Hamilton et al., 2008).

The value of $(24 \pm 9) \mathrm{kJ} \mathrm{mol}^{-1}$ determined here for the effective evaporation enthalpy of the more volatile SOA component (proxy) in the two product model is much lower than the evaporation enthalpies of typical products produced in oxidation of $\alpha$-pinene e.g. pinonaldehyde $(75.5 \pm 5.6) \mathrm{kJ} \mathrm{mol}^{-1}$ (Hallquist et al., 1997), pinic acid $(109 \pm 21) \mathrm{kJ} \mathrm{mol}^{-1}$ (Bilde and Pandis, 2001), transnorpinic acid, (42 \pm 51$) \mathrm{kJ} \mathrm{mol}^{-1}$ (Bilde and Pandis, 2001), and straight chain C3-C9 diacids 91-184 $\mathrm{kJ} \mathrm{mol}^{-1}$ (Bilde et al., 2003; Chattopadhyay and Ziemann, 2005). The value is also lower than effective evaporation enthalpies of about 33 $43 \mathrm{~kJ} \mathrm{~mol}^{-1}$ determined for SOA from the photooxidation of $\alpha$-pinene (Offenberg et al., 2006), values of $42-104 \mathrm{~kJ} \mathrm{~mol}^{-1}$ as estimated by Sheehan and Bowman (2001), and a value of $38 \mathrm{~kJ} \mathrm{~mol}^{-1}$ obtained by analysis of datasets from $7 \mathrm{dif}-$ ferent groups (Svendby et al., 2008). One possible reason for the low value of the effective evaporation enthalpy determined in this paper is that the composition of the group of compounds represented by proxy 2 is changing with temperature. Using the PTR-MS measurements we could indeed observe an increasing partitioning of pinonaldehyde into the condensed phase with decreasing temperature and hence a larger contribution to the semivolatile SOA fraction (Tillmann et al., 2009). Including pinonaldehyde in our model analysis with the molar yields determined by Tillmann et al. (2009) but relying on the vapour pressure parameterisation derived by Hallquist et al. (1997) leads to a stronger temperature dependence of the vapour pressure of the remaining effective semivolatile SOA component as reflected by an increase of the evaporation enthalpy to about $34 \mathrm{~kJ} \mathrm{~mol}^{-1}$. While closer to the expected range this value is still low. On the other hand, applying the vapour pressure recently estimated by Tillmann et al. (2009), which is about two to three orders of magnitude smaller than the value reported by Hallquist et al. (1997), the results are almost consistent with the two product approach. However, since the vapour pressure of pinonaldehyde still seems to have substantial uncertainty this compound was not included explicitly into the model analysis presented in this paper. Clearly, the value of $(59 \pm 8) \mathrm{kJ} \mathrm{mol}^{-1}$ determined here for the evaporation enthalpy of the less volatile SOA component in the two product model is more in line with the evaporation enthalpies of the typical compounds from $\alpha$-pinene oxidation. In conclusion, the vapour pressures and evaporation enthalpies derived in this work for the two SOA forming proxy components are in line with real compound properties with the exception of the low evaporation enthalpy of the more volatile component. 
4.1.4 Aerosol yields as function of aerosol mass and temperature

Using the empirical correlations (6), (7), (10), and (11) fitted to the $\alpha_{i}$ and $K_{i}$ of the two effective SOA forming products of the $\alpha$-pinene oxidation, Eq. (1) can be applied to calculate SOA yields for temperatures in the range between 243 and $313 \mathrm{~K}$ assuming equilibrium conditions and negligible Kelvin effect. In cases where small particles contribute significantly to the SOA mass concentration Eq. (1) will provide an upper limit for the true yield. Figure 7 shows these calculated yields over the SOA mass concentration range from 1 and $1000 \mu \mathrm{g} \mathrm{m}^{-3}$ in comparison with yields determined by using the parameters representative of individual experiments and selected data from the literature. From several previous studies on $\alpha$-pinene ozonolysis e.g. (Hoffmann et al., 1997; Griffin et al., 1999a; Gao et al., 2004; linuma et al., 2004; Presto and Donahue, 2006; Song et al., 2007; Stanier et al., 2007) the data by Cocker et al. (2001), Pathak et al. (2007b), and Shilling et al. (2008) were selected for comparison over the extended temperature, concentration and humidity ranges in our study. All data shown in Fig. 7 were normalised to a density of $1.25 \mathrm{~g} \mathrm{~cm}^{-3}$ for comparison. In order to keep this comparison as general as possible we do not account for the potential influence of the Kelvin effect which depends strongly on the specific conditions of the scenario under consideration, e.g. the particle size distribution. Please note, that we did not correct the organic aerosol mass for its water content. This seems to be reasonable since AMS measurements show average water to SOA mass ratios ranging from $0.06(303 \mathrm{~K})$ to $0.03(253 \mathrm{~K})$ for humid conditions and close to zero for dry conditions (Tillmann et al., 2009). The approximation $M_{O} \approx M_{\mathrm{O}+\mathrm{H} 2 \mathrm{O}}$ should therefore be valid especially for the lower temperatures investigated. The yields determined by Cocker et al. (2001) and Pathak et al. (2007b) are in general agreement with the results obtained in this work but show a little stronger dependence on the organic particle mass concentration. The results of Pathak et al. (2007b) show a weaker temperature dependence compared to this work. The SOA yields obtained at $298 \mathrm{~K}$ for concentrations $1-40 \mu \mathrm{g} \mathrm{m}^{-3}$ by Shilling et al. (2008) are about 50\% higher. The deviation between parameterisation and individual yields visible in Fig. 7 especially for the lowest and highest temperatures reflects the uncertainties of the yield determination. The parameterisation has also been used to construct a temperature dependence plot at constant organic aerosol mass concentration $\left(10 \mu \mathrm{g} \mathrm{m}^{-3}\right)$, see Fig. 8. Please note that the model analysis is based on more data points than those listed in Tables A1 and A2 or shown in Figs. 7 and 14. Typically all data points measured at $\geq 4 \mu \mathrm{g} \mathrm{m}^{-3}$ aerosol mass were successfully fitted by the model. Therefore the parameterisation given should be valid down to $4 \mu \mathrm{g} \mathrm{m}^{-3}$ of organic aerosol mass.

\subsubsection{Role of humidity and $\mathrm{OH}$ scavenger}

From this work a significant impact of humidity on the SOA yields from $\alpha$-pinene ozonolysis, if present at all, can only be taken into consideration for the lowest temperatures investigated. The SOA yields for experiments under very dry conditions at $253 \mathrm{~K}$ are significantly lower than corresponding humid experiments (Fig. 7). This observation can't be explained by water uptake of the SOA for the experiments at higher relative humidities. The AMS shows water contents of the SOA particles of 2-3 wt \% for temperatures between 253 and $243 \mathrm{~K}$ under humid conditions and essentially zero for the dry cases. For higher temperatures water contents of the SOA particles are below 3-6 wt\% (Tillmann et al., 2009). The observed differences in SOA yields for low temperatures are therefore not due to water uptake but more likely due to the influence of water on the gas phase oxidation pathways. This is supported by the observation of substantially reduced yields for pinonaldehyde at dry conditions (Tillmann et al., 2009). The insignificant influence of humidity at $243 \mathrm{~K}$ may be explained by the small difference in absolute water vapour concentrations between the dry and humid experiment. The present result of an insignificant water effect at $303 \mathrm{~K}$ is in contrast to the pronounced positive water effect observed using a flow reactor (Jonsson et al., 2006). The two systems are, however, rather different where the flow reactor study is done at low concentrations, using 2-butanol as $\mathrm{OH}$ scavenger and a much shorter residence time (270 s). In addition, results from a smog chamber study done at room temperature showed a positive effect of water at low reactant concentrations while an insignificant water dependence was observed at high reactant concentrations (Bonn et al., 2002). The effect of water observed at low temperatures is in line with observations in a flow reactor where a positive effect has been observed (Jonsson et al., 2008b). Since the water effect is larger at lower temperatures where the difference in absolute water concentrations is smaller, a physical uptake by SOA seems more likely than an impact of water vapour on chemical kinetics. However, as has been pointed out above, AMS measurements indicate that the physical uptake was minor for all conditions. When it comes to water influencing the chemical composition of SOA this was further supported by volatility measurements of the aerosol as shown in a previous publication for the experiments at $253 \mathrm{~K}$ (Jonsson et al., 2007) and by PTR-MS-measurements of the water dependent partitioning of pinonaldehyde into the particulate phase (Tillmann et al., 2009).

It was suggested that the use of different $\mathrm{OH}$ scavengers can affect the ozonolysis mechanism and thereby the SOA yield (Jenkin, 2004; Keywood et al., 2004; Docherty et al., 2005). As can be seen from the data in Table A1 and Fig. 9 the SOA yields in the presence of cyclohexane or 2butanol as radical scavengers are the same within their error limits, with slightly higher yields in the presence of 2butanol. For experiments without $\mathrm{OH}$ scavenger the effect 


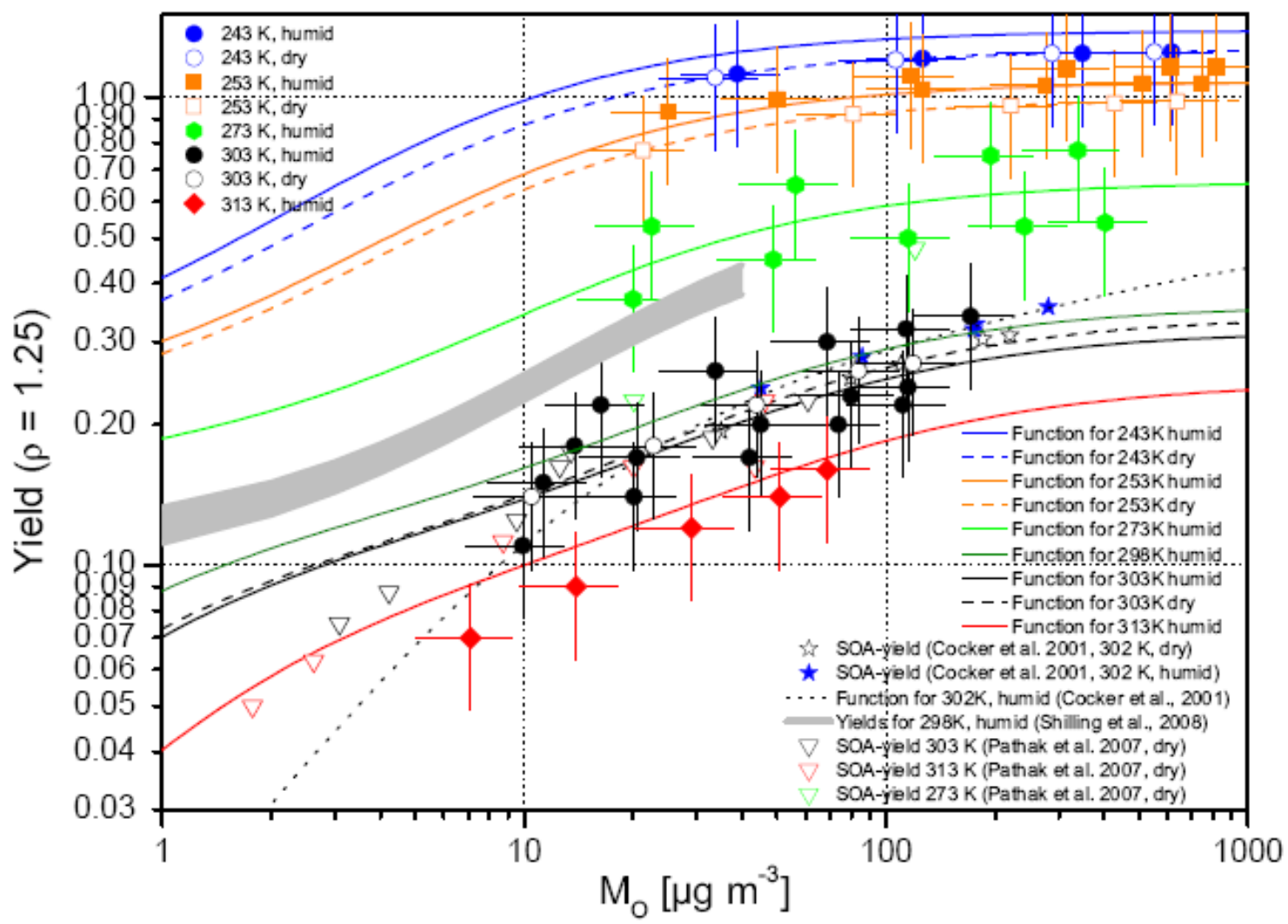

Fig. 7. Dependence of SOA yields from $\alpha$-pinene ozonolysis on temperature and on organic aerosol mass $\left(M_{o}\right)$. Values calculated using the average parameters of the two products (lines) and Eq. (1) are compared to literature data (stars: Cocker et al., 2001; triangles: Pathak et al., 2007b; grey area: Shilling et al., 2008).

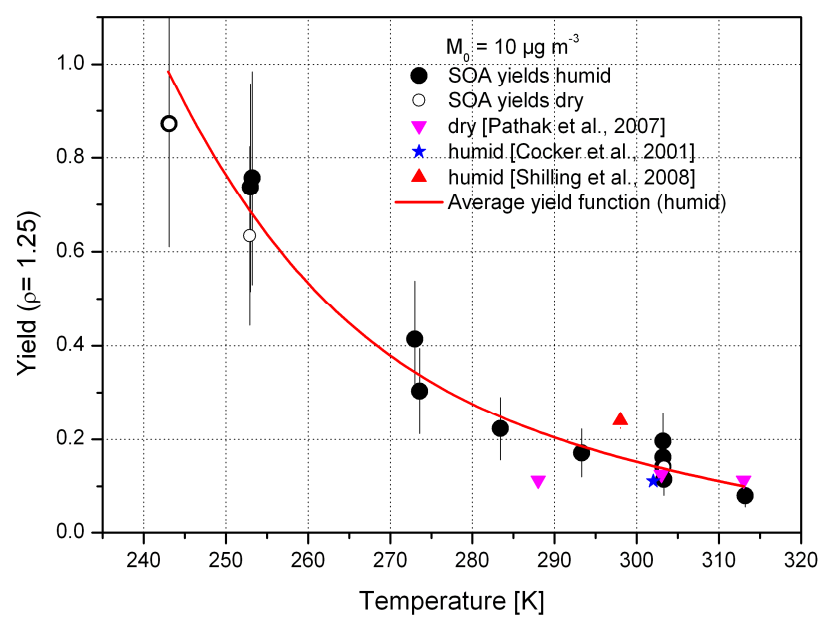

Fig. 8. Temperature dependence of SOA yields from $\alpha$-pinene ozonolysis for an organic aerosol mass concentration $\left(M_{o}\right)$ fixed to $10 \mu \mathrm{g} \mathrm{m}^{-3}$. Data from individual experiments (circles) are compared to selected literature data and the parameterisation obtained from fitting functions to the values determined for $\alpha_{i}$ and $K_{i}$. was pronounced and the SOA yield was higher by a factor of about 2 . The effects at $303 \mathrm{~K}$ thus resemble previous observations for $\alpha$-pinene and other endocyclic terpenes (Keywood et al., 2004; Docherty et al., 2005; Iinuma et al., 2005; Jonsson et al., 2008a). At $243 \mathrm{~K}$ the influence of the scavenger shows the same trend but the differences in SOA yield, especially compared to the case without scavenger, seem to be smaller at low temperatures (Jonsson et al., 2008b) although Tillmann et al. (2009) provide clear evidence that $\mathrm{OH}$ radicals are formed in the ozonolysis reaction of $\alpha$-pinene even at the lowest temperatures.

\subsection{SOA from limonene ozonolysis}

The formation of SOA from the ozonolysis of limonene was investigated in the temperature range $253-313 \mathrm{~K}$, for total organic aerosol mass concentrations ranging up to about $740 \mu \mathrm{g} \mathrm{m}^{-3}$, and for water mixing ratios ranging from a few ppm to several $10^{4} \mathrm{ppm}$. The typical behaviour of the measured trace gas and particle concentrations as shown in Figs. 10 and 11 is comparable to those observed for $\alpha$-pinene. The limonene concentrations rapidly decrease after addition 
Table 2. Mass stoichiometric yield parameters $\left(\alpha_{i}\right)$, vapour pressures $\left(p_{i}\right)$, partitioning coefficients $\left(K_{i}\right)$, and effective accommodation coefficients $\left(\gamma_{i}\right)$ determined for two effective SOA forming products of the limonene ozonolysis.

\begin{tabular}{ccccccccccc}
\hline Experiment & $\begin{array}{c}T \\
{[\mathrm{~K}]}\end{array}$ & $\begin{array}{c}\mathrm{RH} \\
{[\%]}\end{array}$ & $\alpha_{1}$ & $\alpha_{2}$ & $\begin{array}{c}p_{1} \\
{[\mathrm{bar}]}\end{array}$ & $\begin{array}{c}p_{2} \\
{[\mathrm{bar}]}\end{array}$ & $\begin{array}{c}K_{1} \\
{\left[\mathrm{~m}^{3} \mu \mathrm{g}^{-1}\right]}\end{array}$ & $\begin{array}{c}K_{2} \\
{\left[\mathrm{~m}^{3} \mu \mathrm{g}^{-1}\right]}\end{array}$ & $\gamma_{1}^{\mathrm{a}}$ & $\gamma_{2}^{\mathrm{a}}$ \\
\hline SOA03-10 & 313.3 & 20 & 0.178 & 0.395 & $1.4 \mathrm{E}-10$ & $7.0 \mathrm{E}-09$ & 1.1 & 0.021 & 0.30 & 1.00 \\
SOA06-4 & 303.0 & 43 & $(0.185)$ & 0.173 & $7.0 \mathrm{E}-11$ & $5.0 \mathrm{E}-09$ & 2.0 & 0.028 & 0.20 & 1.00 \\
SOA03-8 & 293.4 & 40 & 0.171 & 0.618 & $(1.0 \mathrm{E}-10)$ & $3.5 \mathrm{E}-09$ & $(1.4)$ & 0.041 & 0.20 & 0.90 \\
SOA05-4 & 293.2 & 42 & 0.171 & 0.556 & $3.0 \mathrm{E}-11$ & $3.5 \mathrm{E}-09$ & 4.7 & 0.041 & 0.20 & 0.70 \\
SOA05-3 & 293.3 & 0.02 & 0.171 & 0.556 & $3.0 \mathrm{E}-11$ & $3.5 \mathrm{E}-09$ & 4.7 & 0.041 & 0.20 & 0.90 \\
SOA06-5 & 273.2 & 70 & 0.12 & 0.791 & $7.0 \mathrm{E}-12$ & $1.5 \mathrm{E}-09$ & 19.1 & 0.089 & 0.20 & 0.30 \\
SOA05-5 & 252.8 & 43 & 0.082 & 1.013 & $8.5 \mathrm{E}-13$ & $7.0 \mathrm{E}-10$ & 146.1 & 0.177 & 0.10 & 0.03 \\
SOA05-6 & 252.8 & 0.3 & 0.082 & 0.729 & $8.5 \mathrm{E}-13$ & $7.0 \mathrm{E}-10$ & 145.7 & 0.177 & 0.10 & 0.04 \\
\hline
\end{tabular}

${ }^{\text {a }}$ Values strongly influenced by changes in chemical reaction mechanism. Values in brackets could not be determined unambiguously.

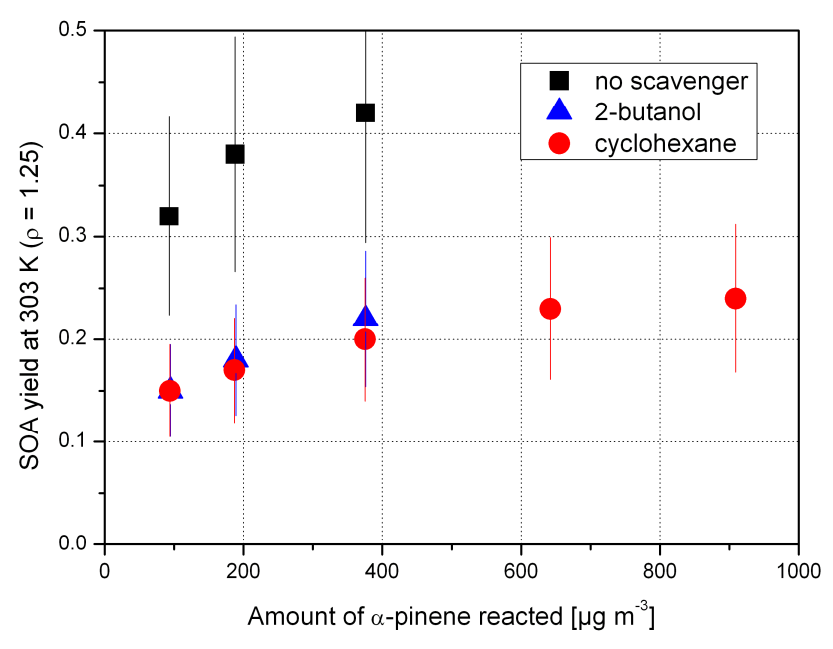

Fig. 9. Influence of the $\mathrm{OH}$ scavenger on the SOA yields determined for $\alpha$-pinene in experiments SOA05-1 (cyclohexane), SOA05-12 (no scavenger), and SOA06-1 (2-butanol) at $303 \mathrm{~K}$.

to the excess of ozone. The kinetics of the limonene + ozone reaction was reproduced without significant discrepancies extrapolating the temperature dependence of the rate coefficients from the literature (Khamaganov and Hites, 2001). In contrast to the experiments with $\alpha$-pinene particle nucleation occurred already for lower ozone to limonene ratios. At $303 \mathrm{~K}$ significant new particle formation occurred only at the first addition of limonene whereas at $253 \mathrm{~K}$ new particles were also formed in all subsequent steps. However, the dominant mass fraction always condensed on those particles which had formed in the first step. The limonene data were analysed in the same way as described for $\alpha$-pinene using the COSIMA-SOA model. The wall loss correction for the limonene experiments did not show significant differences compared to the $\alpha$-pinene experiments. The results on SOA from limonene are described and summarised below with respect to the density, physical parameters derived for the two components and the corresponding aerosol yields.

4.2.1 Density of the organic aerosol from
limonene ozonolysis

The scatter in effective densities is larger in the case of SOA from limonene than for SOA from $\alpha$-pinene. No simple relation was found between effective density and temperature. Taking into account the larger scatter in comparison with the densities derived for SOA from $\alpha$-pinene an average density of $(1.3 \pm 0.2) \mathrm{g} \mathrm{cm}^{-3}$ was chosen for the data evaluation in this paper. This is in agreement with a value of $(1.3 \pm 0.09) \mathrm{g} \mathrm{cm}^{-3}$ (Wirtz and Martin-Reviejo, 2003) which was obtained by combining SMPS and TEOM data at $299 \mathrm{~K}$ but lower than the value of $(1.56 \pm 0.1) \mathrm{g} \mathrm{cm}^{-3}$ (Kostenidou et al., 2007) obtained by combining AMS and SMPS data at $288 \mathrm{~K}$. The effective density of limonene SOA exhibits a dependence on elapsed time which is correlated with a change in the fractional abundance of $m / z=44$ in the aerosol mass spectral patterns. Typically $m / z=44$ is considered a marker for the oxidized fraction of the organic aerosol OOA (Zhang et al., 2005). Mass spectral properties of the SOA and its relation to chemical and physical properties will be discussed in more detail in a separate paper.

\subsubsection{Parameters of two effective SOA forming products}

Using the COSIMA-SOA model the parameters for two effective components were obtained by fitting the model to the trace gas and particle concentrations as well as the size distributions. Table 2 summarises the parameters determined for the different experiments with limonene. The experimental 


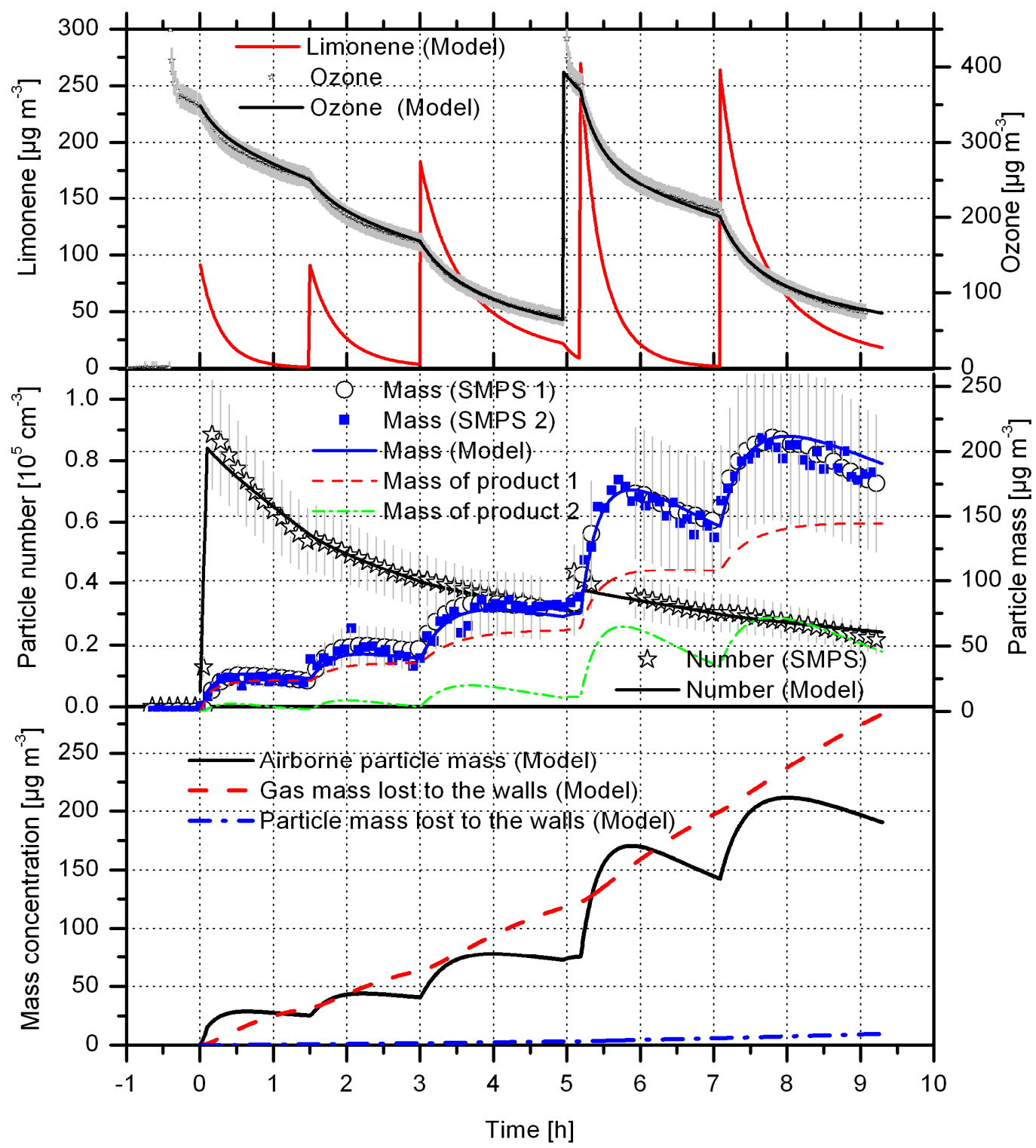

Fig. 10a. Evolution of measured trace gas, particle number, and mass concentrations (symbols) and model results including wall losses (lines) for experiment SOA03-10 at $313 \mathrm{~K}$.

conditions and calculated yields are summarised in Table A2. Not all experiments listed in Table A2 provided a database sufficient for a detailed model analysis. In the model analysis the same values as for the experiments with $\alpha$-pinene were used for molecular masses, surface tensions, and diffusion coefficients of the two components. This appears reasonable since $M W_{1}=186 \mathrm{~g} / \mathrm{mol}$ and $M W_{2}=168 \mathrm{~g} / \mathrm{mol}$ also correspond to typical monomeric oxidation products of limonene such as limonic acid or limononaldehyde (Glasius et al., 2000; Leungsakul et al., 2005; Walser et al., 2008). Furthermore, the molecular subgroups that could be considered as intermolecular interaction sites within the framework of a group contribution approach are similar for the ozonolysis product species of both terpenes. Also for limonene the values of the effective accommodation coefficient for the more volatile component are low at low temperature $(\sim 253 \mathrm{~K})$ which again is emphasising the slower oxidation kinetics at this temperature. Figure 12 shows the temperature dependence of the vapour pressures $\left(p_{1} ; p_{2}\right)$ of the two effective SOA forming products of the ozonolysis of limonene while Fig. 13 shows the yields of the two effective SOA forming products $\left(\alpha_{1} ; \alpha_{2}\right)$ and the partitioning coefficients $\left(K_{1} ; K_{2}\right)$. In contrast to the $\alpha$-pinene case the mass stoichiometric yield coefficient of the non-volatile component in the two product 


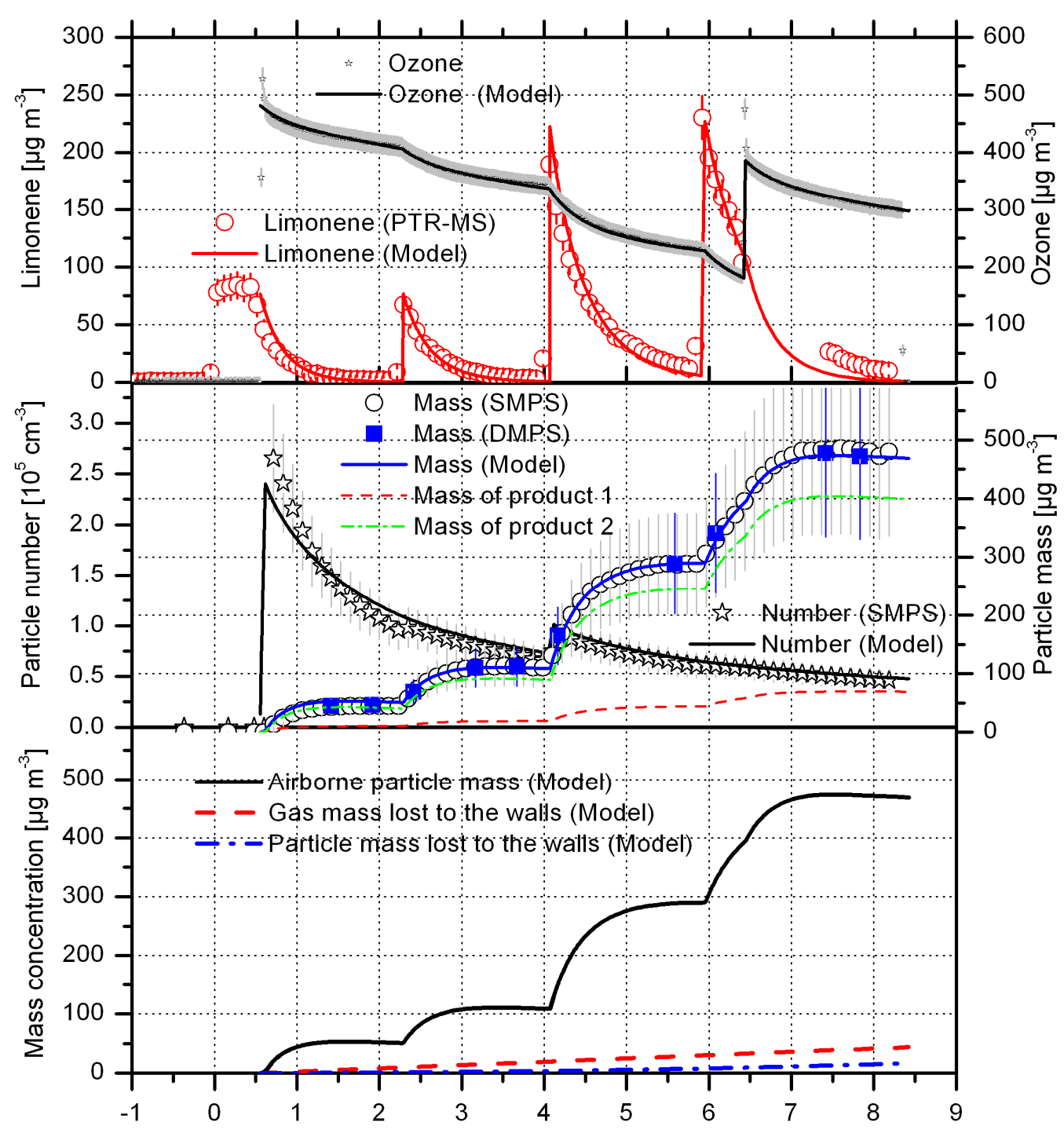

Time [h]

Fig. 10b. Evolution of measured trace gas, particle number, and mass concentrations (symbols) and model results including wall losses (lines) for experiment SOA06-5 at $273 \mathrm{~K}$. Please note that this experiment started $33 \mathrm{~min}$ after injection of limonene by addition of ozone.

model has a positive temperature dependence. The coefficient of the volatile component increases from about 0.4 up to 1 with the temperature decreasing from 313 to $253 \mathrm{~K}$. For limonene the dependencies are approximately linear in the studied temperature range for both effective SOA components. Note however, that $\alpha_{2}$ appears to be humidity dependent at low temperatures. The parameterisations of the mass stoichiometric yield coefficients $\left(\alpha_{i}\right)$ derived from the individual experiments are valid for the temperature range 253-313 K and for humid conditions:

$\alpha_{1}=-(0.395 \pm 0.203)+(0.0019 \pm 0.0007) * T$

$\alpha_{2}=(3.53 \pm 1.32)-(0.010 \pm 0.004) * T$
The uncertainties for $\alpha_{1}$ are estimated to $\pm 60 \%$ for 273 $253 \mathrm{~K}$ and $\pm 30 \%$ for temperatures above. The uncertainties for $\alpha_{2}$ are estimated to $\pm 30 \%$ for $313-253 \mathrm{~K}$. The vapour pressures for the two effective SOA forming products are given in Table 2 and the resulting temperature dependence is shown by the Clausius - Clapeyron plot in Fig. 12. The following parameterisations of the vapour pressures $\left(p_{i}\right)$ were derived from the individual experiments for the temperature range $253-313 \mathrm{~K}$ and for humid conditions:

$$
\begin{aligned}
& \ln p_{1}[\mathrm{bar}]=-(1.6 \pm 2.9)-(6613 \pm 831) / \mathrm{T} \\
& \ln p_{2}[\mathrm{bar}]=-(9.2 \pm 2.5)-(3013 \pm 715) / \mathrm{T}
\end{aligned}
$$




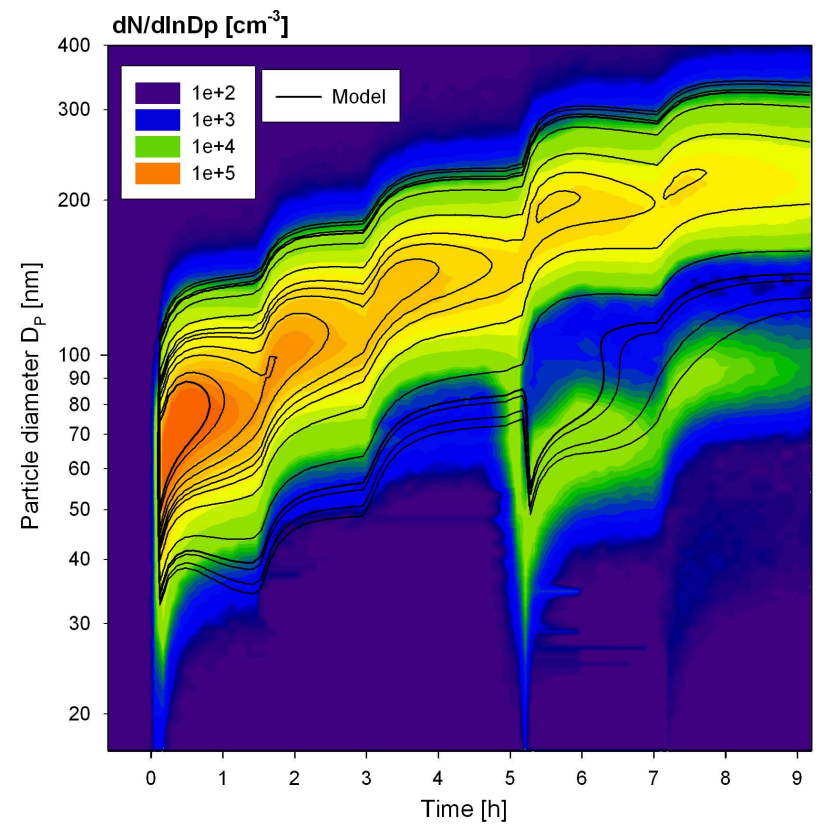

Fig. 11a. Evolution of the measured (colour code) and modelled (lines) particle size distribution for experiment SOA03-10 with limonene at $313 \mathrm{~K}$.

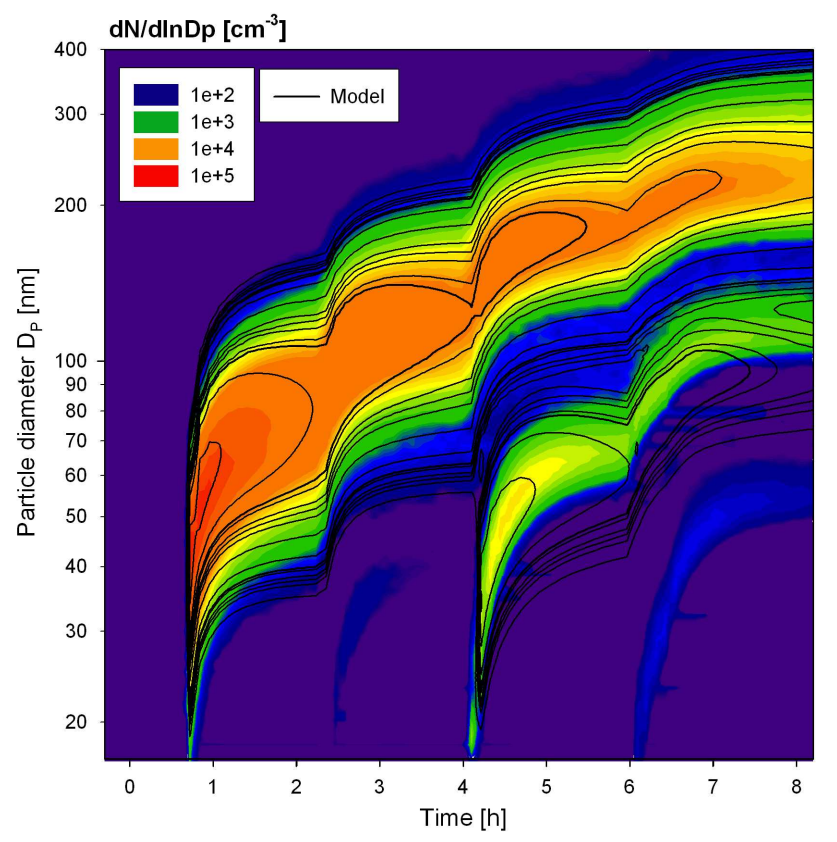

Fig. 11b. Evolution of the measured (colour code) and modelled (lines) particle size distribution for experiment SOA06-5 with limonene at $273 \mathrm{~K}$.

These equations provide vapour pressures in the temperature range $253-313 \mathrm{~K}$ for the less and more volatile component ranging from $8.5 \times 10^{-13}$ to $1.4 \times 10^{-10}$ bar and $7 \times 10^{-10}$ to $7 \times 10^{-9}$ bar, respectively. The following parameterisations

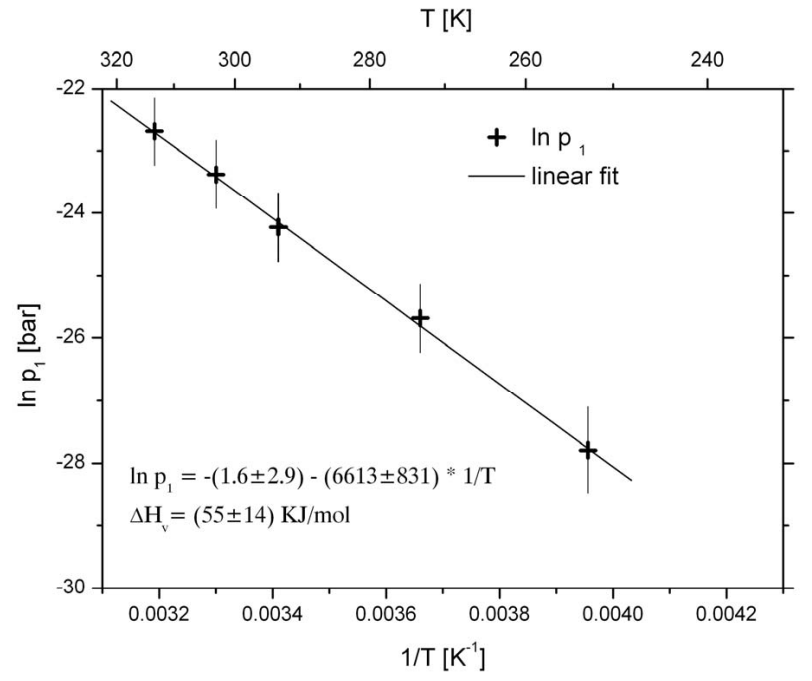

Fig. 12a. Temperature dependence of the vapour pressure of the less volatile SOA forming product of the ozonolysis of limonene.

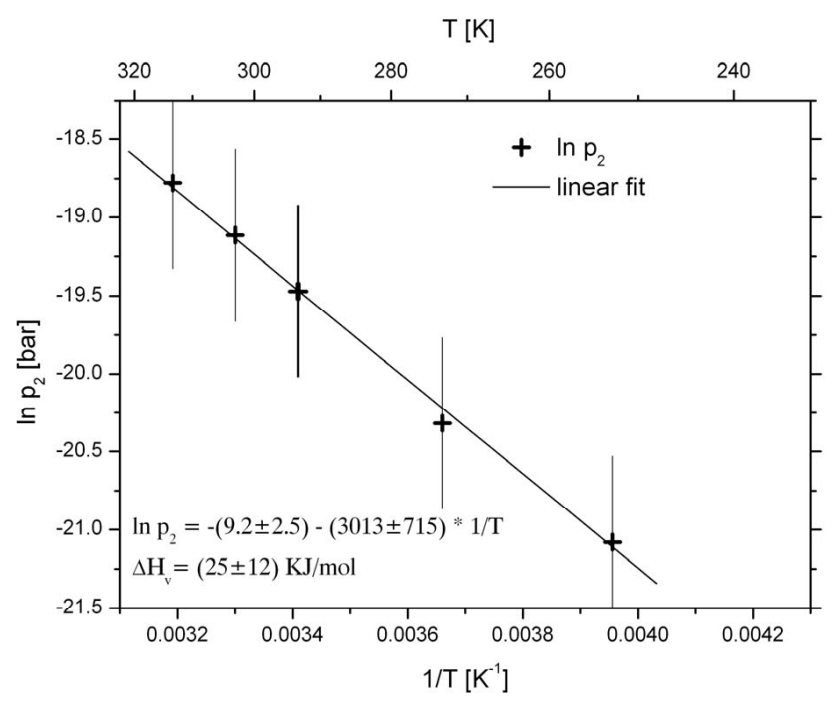

Fig. 12b. Temperature dependence of the vapour pressure of the more volatile SOA forming product of the ozonolysis of limonene.

of the partitioning coefficients $\left(K_{i}\right)$ were derived from the individual experiments for the temperature range 253-313 K and for humid conditions:

$$
\begin{aligned}
& \ln K_{1}\left[m^{3} \mu g^{-1}\right]=-(26.7 \pm 2.2)+\ln \mathrm{T}+(6580 \pm 732) / T(16) \\
& \ln K_{2}\left[m^{3} \mu g^{-1}\right]=-(20.0 \pm 2.2)+\ln \mathrm{T}+(3240 \pm 643) / T(17)
\end{aligned}
$$

The uncertainties estimated for $p_{1}$ and $K_{1}$ are $\pm 50 \%$ for $313-273 \mathrm{~K}$ and $\pm 100 \%$ for temperatures below. The uncertainties estimated for $p_{2}$ and $K_{2}$ are $\pm 50 \%$ for 313 $253 \mathrm{~K}$. Combining Eqs. $(1,12,13,16,17)$ allows to calculate 


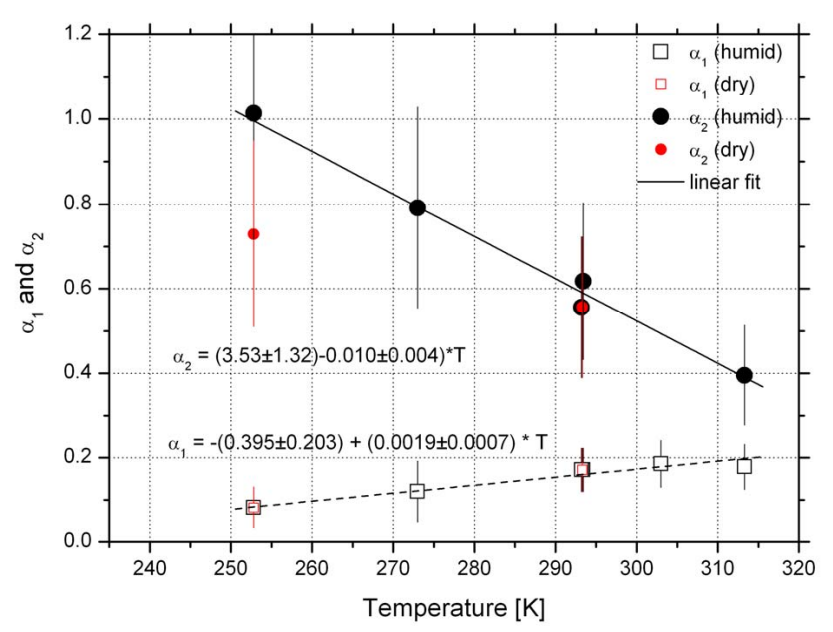

Fig. 13a. Temperature dependence of the mass stoichiometric yield coefficients of the two effective SOA forming reaction products of the ozonolysis of limonene.

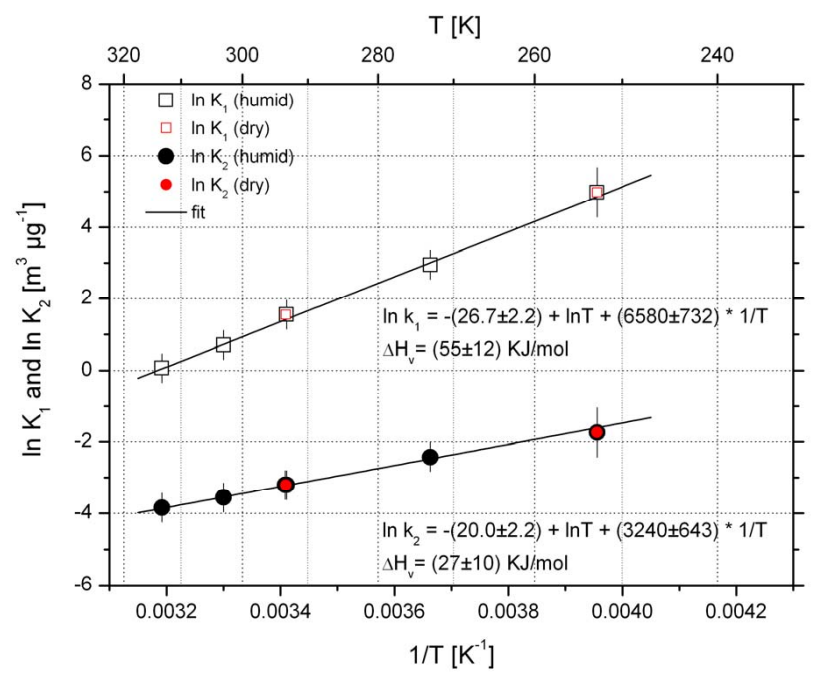

Fig. 13b. Temperature dependence of the partitioning coefficients of the two effective SOA forming reaction products of the ozonolysis of limonene.

average SOA yields for the limonene ozonolysis under humid conditions in the given temperature range. In Table A2 yield values calculated this way are compared to values calculated using Eq. (1) and the stoichiometric and partitioning coefficients obtained for the individual experiments (Table 2). The value of $(25 \pm 12) \mathrm{kJ} \mathrm{mol}^{-1}$ determined here for the effective evaporation enthalpy of the volatile SOA component in the two product model is comparable to the evaporation enthalpy for the corresponding $\alpha$-pinene component and also much lower than the evaporation enthalpies of reference compounds as discussed for $\alpha$-pinene. In addition, the evaporation enthalpy of the low volatility SOA component in the two product model of $(55 \pm 14) \mathrm{kJ} \mathrm{mol}^{-1}$ resembles the

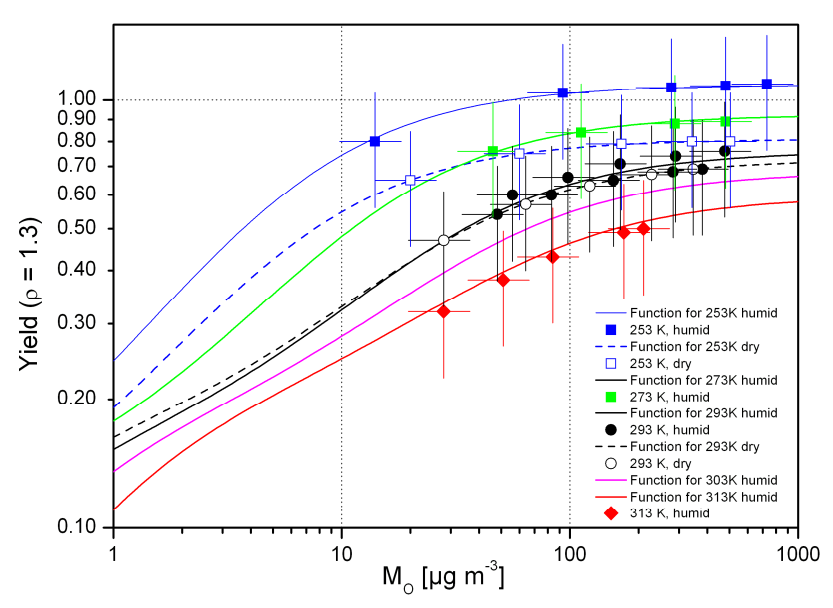

Fig. 14. Dependence of SOA yields from limonene ozonolysis on temperature and on organic aerosol mass $\left(M_{O}\right)$. The values are calculated using the average parameters of the two products (lines) and Eq. (1).

evaporation enthalpy of $(59 \pm 8) \mathrm{kJ} \mathrm{mol}^{-1}$ for the low volatility SOA component of $\alpha$-pinene.

\subsubsection{Aerosol yields as function of aerosol mass and tem- perature}

Using the functions fitted to the parameters of the two effective SOA forming products of the limonene ozonolysis Eq. (1) can be used to calculate SOA yields for temperatures in the range between 253 and $313 \mathrm{~K}$ and for organic aerosol masses between 1 and $1000 \mu \mathrm{g} \mathrm{m}^{-3}$. We assume furthermore that the SOA from limonene does not include significant amounts of water in agreement with results of AMS measurements showing that the water content of the SOA is $6 \mathrm{wt} \%$ or lower. Figures 14 and 15 show the average and individual yields of SOA from limonene for selected temperatures as function of the organic aerosol mass concentration, and as function of temperature for a fixed aerosol mass concentration of $10 \mu \mathrm{g} \mathrm{m}^{-3}$, respectively. The water dependence of SOA production for ozonolysis of limonene resembles that of $\alpha$-pinene. Again a significant positive water effect was observed for $253 \mathrm{~K}$ but no significant influence for $293 \mathrm{~K}$. This is in agreement with the results of Bonn et al. (2002) who did not find any effect of added water on the SOA yield of limonene at room temperature.

\subsection{Comparison of parameters for SOA from $\alpha$-pinene and limonene ozonolysis}

SOA yields are generally higher for limonene compared to $\alpha$-pinene near room temperature (cf. Fig. 15). Due to the stronger temperature dependence of SOA yields from $\alpha$ pinene the yield values reach similar levels for both terpenes 
at about $250 \mathrm{~K}$. It should be noted that limonene has two double bonds that can react with ozone. Indeed, heterogeneous oxidation of an unsaturated product has been proposed to be involved in SOA formation from limonene (Zhang et al., 2006). The water dependences of the SOA yields from ozonolysis of limonene and $\alpha$-pinene are very similar showing a significant positive water effect for the lowest temperatures but no significant influence for room temperature.

\section{Conclusions}

This work provides a substantial amount of new data on the temperature dependence of aerosol yields from the ozonolysis of $\alpha$-pinene (243-313 K) and limonene (252-313), as well as other important physico-chemical properties of the SOAs and their precursors. It confirms earlier studies demonstrating that SOA yields Y, defined by Eq. (1) in Sect. 3, depend on organic aerosol mass concentration and inversely on temperature. The experimental range is, however, extended to significantly lower temperatures where the SOA yields are found to approach their theoretical upper bounds. It was also demonstrated that the SOA yield from $\alpha$-pinene, which produces less SOA near room temperature, has stronger temperature dependence than limonene which produces significant amounts of SOA already at room temperature and above. The SOA yields increase by up to a factor of $\sim 5$ to 10 for $\alpha$-pinene and by a factor of $\sim 2.5$ for limonene from 313 to $243 \mathrm{~K}$ and 313 to $253 \mathrm{~K}$, respectively. The experimental data were evaluated extensively using the COSIMA-SOA model. By using a two condensable product approach for either terpene, selected parameters were extracted for every experiment, i.e. individual yield parameters $\left(\alpha_{i}\right)$, vapour pressures $\left(p_{i}\right)$, partitioning coefficients $\left(K_{i}\right)$, and effective accommodation coefficients $\left(\gamma_{i}\right)$. This work thus provides parameterised temperature dependencies of those values that can easily be applied to calculate SOA formation by the ozonolysis of these terpenes under tropospheric conditions. We emphasize, however, that the empirical expressions are only valid within the error limits of the experimental data and should not be extrapolated beyond the given ranges of experimental conditions. Please note that the Kelvin effect, although often negligible with respect to predicted SOA yields and airborne mass concentrations, may strongly influence the evolutions of particle number concentration and size distribution, the latter both being relevant when considering e.g. aerosol optical properties or particle-cloud interactions. Furthermore, the densities of both SOA types were determined by combining AMS and SMPS measurements. For $\alpha$-pinene the effective density scattered around a constant value under all conditions and an average density of $(1.25 \pm 0.1) \mathrm{g} \mathrm{cm}^{-3}$ was obtained. For limonene the density measurements showed considerably more scatter and a value of $(1.3 \pm 0.2) \mathrm{g} \mathrm{cm}^{-3}$ was used for the evaluation process.

The parameters derived in this work for the two condensable product proxies were compared to observations of se-

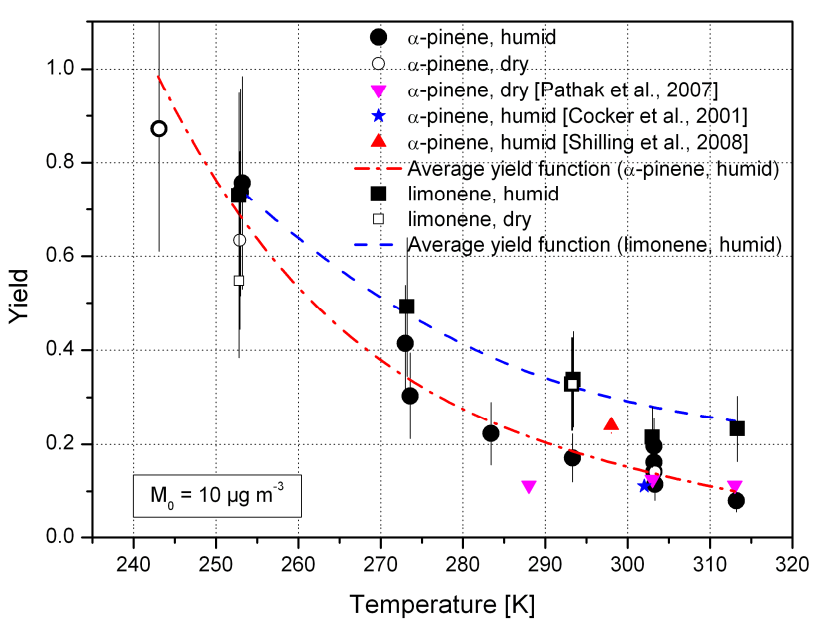

Fig. 15. Temperature dependence of SOA yields from ozonolysis of $\alpha$-pinene and limonene for an organic aerosol mass concentration $\left(M_{o}\right)$ fixed to $10 \mu \mathrm{g} \mathrm{m}^{-3}$. Data from individual experiments (symbols) are compared to selected literature data and the parameterisations obtained from fitting functions to the values determined for $\alpha_{i}$ and $K_{i}$. Densities of 1.25 and $1.3 \mathrm{~g} \mathrm{~cm}^{-3}$ were used for $\alpha$ pinene and limonene SOA, respectively.

lected pure compounds known to be produced in the oxidation of terpenes. It was demonstrated that the derived vapour pressures $p_{i}$ are in line with typical vapour pressures of individual low volatile oxidation products of terpenes even though some values were considerably lower than any vapour pressure measured so far for SOA components. However, this is not unexpected since some organic compounds with extremely low vapour pressures would be challenging to identify in ambient SOA. Using volatility measurements of the integrated SOA Jonsson et al. (2007) could demonstrate that at least a few $\%$ of the SOA mass are non-volatile, i.e. did not evaporate when exposed to $583 \mathrm{~K}$ in a VTDMA. Our results imply that humidity has a significant influence on SOA yields for temperatures as low as $253 \mathrm{~K}$ but not near room temperature. Pertinent mechanistic and kinetic considerations and part of the gas phase analysis are presented elsewhere (Tillmann et al., 2009). Regarding aerosol formation kinetics, some relatively low effective accommodation coefficients extracted in the present work imply the involvement of rate limiting steps in the formation of the condensable SOA precursors at low temperatures, also manifested as a time delay in SOA formation in relation to terpene consumption.

The data presented here render a solid basis for the parameterisation of SOA formation from the ozonolysis of $\alpha$ pinene and limonene in regional as well as global aerosol predicting models. They may also serve as a starting point for further investigations into SOA formation mechanisms including both chemical and physical aspects. 


\section{Appendix A}

\section{List of experimental conditions}

Table A1. Experimental conditions of experiments with $\alpha$-pinene and SOA yields calculated.

\begin{tabular}{|c|c|c|c|c|c|c|c|}
\hline Exp.-No. & Step ${ }^{\mathrm{e}}$ & $\begin{array}{c}T \\
{[\mathrm{~K}]}\end{array}$ & $\begin{array}{l}\mathrm{RH}^{\mathrm{d}} \\
{[\%]}\end{array}$ & $\begin{array}{l}\text { Terpene }^{\mathrm{c}} \\
{\left[\mu \mathrm{g} \mathrm{m}^{-3}\right]}\end{array}$ & $\begin{array}{l}\mathrm{M}_{\mathrm{Org}}^{\mathrm{f}} \\
{\left[\mu \mathrm{g} \mathrm{m}^{-3}\right]}\end{array}$ & $\begin{array}{l}\text { SOA Yieldg } \\
\text { individual }\end{array}$ & $\begin{array}{l}\text { SOA Yield } \\
\text { average }\end{array}$ \\
\hline \multirow[t]{5}{*}{ SOA03-5 } & 1 & $313.3 \pm 0.5$ & $18-15$ & $92 \pm 9$ & 7.1 & 0.07 & 0.09 \\
\hline & 2 & & & $92 \pm 9$ & 13.9 & 0.09 & 0.11 \\
\hline & 3 & & & $183 \pm 18$ & 29.0 & 0.12 & 0.13 \\
\hline & 4 & & & $270 \pm 20$ & 50.9 & 0.14 & 0.16 \\
\hline & 5 & & & $270 \pm 20$ & 68.8 & 0.16 & 0.17 \\
\hline \multirow[t]{5}{*}{ SOA03-4 } & 1 & $303.3 \pm 0.5$ & $40-37$ & $92 \pm 9$ & 9.9 & 0.11 & 0.14 \\
\hline & 2 & & & $92 \pm 9$ & 20.1 & 0.14 & 0.17 \\
\hline & 3 & & & $183 \pm 18$ & 41.9 & 0.17 & 0.20 \\
\hline & 4 & & & $270 \pm 20$ & 73.8 & 0.20 & 0.23 \\
\hline & 5 & & & $270 \pm 20$ & 111.3 & 0.22 & 0.25 \\
\hline \multirow[t]{5}{*}{ SOA05-1 } & 1 & $303.2 \pm 0.2$ & $48-41$ & $94 \pm 9$ & 11.3 & 0.15 & 0.14 \\
\hline & 2 & & & $93 \pm 9$ & 20.5 & 0.17 & 0.17 \\
\hline & 3 & & & $188 \pm 19$ & 45.0 & 0.20 & 0.21 \\
\hline & 4 & & & $267 \pm 20$ & 80.0 & 0.23 & 0.24 \\
\hline & 5 & & & $267 \pm 20$ & 115.0 & 0.24 & 0.25 \\
\hline \multirow[t]{5}{*}{ SOA05-2 } & 1 & $303.3 \pm 0.2$ & 0.02 & $93 \pm 9$ & 10.5 & 0.14 & - \\
\hline & 2 & & & $93 \pm 9$ & 22.8 & 0.18 & - \\
\hline & 3 & & & $186 \pm 19$ & 43.8 & 0.22 & - \\
\hline & 4 & & & $268 \pm 20$ & 83.8 & 0.26 & - \\
\hline & 5 & & & $268 \pm 20$ & 118.8 & 0.27 & - \\
\hline \multirow[t]{3}{*}{$\mathrm{SOA} 05-12^{\mathrm{a}}$} & 1 & $303.2 \pm 0.2$ & $44-43$ & $93 \pm 9$ & 28.8 & 0.32 & - \\
\hline & 2 & & & $95 \pm 9$ & 55.0 & 0.38 & - \\
\hline & 3 & & & $188 \pm 19$ & 103.8 & 0.42 & - \\
\hline \multirow[t]{5}{*}{ SOA05-13 } & 1 & $303.2 \pm 0.5$ & $45-38$ & $95 \pm 9$ & 16.3 & 0.22 & 0.16 \\
\hline & 2 & & & $95 \pm 9$ & 33.8 & 0.26 & 0.19 \\
\hline & 3 & & & $190 \pm 19$ & 68.8 & 0.30 & 0.23 \\
\hline & 4 & & & $272 \pm 20$ & 113.8 & 0.32 & 0.25 \\
\hline & 5 & & & $272 \pm 20$ & 171.3 & 0.34 & 0.27 \\
\hline \multirow[t]{3}{*}{ SOA06-1 ${ }^{b}$} & 1 & $303 \pm 0.1$ & $48-44$ & $95 \pm 9$ & 12.5 & 0.15 & - \\
\hline & 2 & & & $94 \pm 9$ & 27.5 & 0.18 & - \\
\hline & 3 & & & $187 \pm 19$ & 53.8 & 0.22 & - \\
\hline SOA06-2 $2^{\mathrm{a}}$ & 1 & $303.2 \pm 0.1$ & $45-43$ & $94 \pm 9$ & 20.0 & - & - \\
\hline SOA06-3 & 1 & $303.2 \pm 0.1$ & $46-44$ & $95 \pm 9$ & 13.8 & 0.18 & 0.15 \\
\hline \multirow[t]{4}{*}{ SOA03-0 } & 1 & $297.3 \pm 0.2$ & $36-33$ & $90 \pm 9$ & 8.8 & - & 0.16 \\
\hline & 2 & & & $184 \pm 18$ & 31.3 & - & 0.23 \\
\hline & 3 & & & $268 \pm 20$ & 77.5 & - & 0.28 \\
\hline & 4 & & & $268 \pm 20$ & 118.8 & - & 0.30 \\
\hline \multirow[t]{2}{*}{ SOA05-0 } & 1 & $296.5 \pm 0.6$ & $36-34$ & $269 \pm 20$ & 51.3 & - & 0.26 \\
\hline & 2 & & & $269 \pm 20$ & 105.0 & - & 0.30 \\
\hline \multirow[t]{5}{*}{ SOA03-3 } & 1 & $293.3 \pm 0.5$ & $36-34$ & $91 \pm 9$ & 12.5 & 0.18 & 0.20 \\
\hline & 2 & & & $92 \pm 9$ & 26.3 & 0.23 & 0.24 \\
\hline & 3 & & & $183 \pm 18$ & 60.0 & 0.29 & 0.30 \\
\hline & 4 & & & $269 \pm 20$ & 115.0 & 0.32 & 0.34 \\
\hline & 5 & & & $269 \pm 20$ & 187.5 & 0.34 & 0.36 \\
\hline \multirow[t]{3}{*}{ SOA03-2 } & 1 & $283.4 \pm 0.5$ & $32-30$ & $89 \pm 9$ & 15.0 & 0.26 & 0.28 \\
\hline & 2 & & & $91 \pm 9$ & 33.8 & 0.33 & 0.35 \\
\hline & 3 & & & $186 \pm 19$ & 87.5 & 0.40 & 0.43 \\
\hline
\end{tabular}

If not stated otherwise all experiments were done with about $500 \mathrm{ppm}$ cyclohexane as $\mathrm{OH}$ scavenger and $100-300 \mathrm{ppb}$ of ozone at total pressures between 990 and $1015 \mathrm{hPa}{ }^{\mathrm{a}} \mathrm{No}$ $\mathrm{OH}$ scavenger added. ${ }^{\mathrm{b}}$ 2-Butanol used as $\mathrm{OH}$ scavenger. ${ }^{\mathrm{c}}$ Amounts added to the simulation chamber. ${ }^{\mathrm{d}}$ During the experiments the relative humidity was changed by adding dry air to replace sample losses. ${ }^{\mathrm{e}}$ Steps of subsequent addition of terpene to the reaction system . ${ }^{\mathrm{f}}$ Maximum amount of organic aerosol mass present in that reaction step $\left(\rho=1.25 \mathrm{~g} \mathrm{~cm}{ }^{-3}\right.$ ). $\mathrm{g}$ Yields as calculated using Eq. (1) with the individual values determined for $\alpha_{i}$ and $K_{i}$ (c.f. Table 1). ${ }^{\mathrm{h}}$ Yields as calculated using Eqs. (1, 6, 7, 10, 11) with the parameterised values for $\alpha_{i}$ and $K_{i}$ for humid conditions and with cyclohexane as scavenger. 
Table A1. Continued.

\begin{tabular}{|c|c|c|c|c|c|c|c|}
\hline Exp.-No. & Step $^{\mathrm{e}}$ & $\begin{array}{c}T \\
{[\mathrm{~K}]}\end{array}$ & $\begin{array}{l}\mathrm{RH}^{\mathrm{d}} \\
{[\%]}\end{array}$ & $\begin{array}{l}\text { Terpene }{ }^{\mathrm{c}} \\
{\left[\mu \mathrm{g} \mathrm{m}^{-3}\right]}\end{array}$ & $\begin{array}{l}\mathrm{M}_{\mathrm{Org}}^{\mathrm{f}} \\
{\left[\mu \mathrm{g} \mathrm{m}^{-3}\right]}\end{array}$ & $\begin{array}{l}\text { SOA Yield } \\
\text { individual }\end{array}$ & $\begin{array}{l}\text { SOA Yield }{ }^{\mathrm{h}} \\
\text { average }\end{array}$ \\
\hline & 4 & & & $269 \pm 20$ & 171.3 & 0.44 & 0.47 \\
\hline & 5 & & & $269 \pm 20$ & 280.0 & 0.46 & 0.48 \\
\hline \multirow[t]{5}{*}{ SOA03-1 } & 1 & $273.6 \pm 0.5$ & $31-28$ & $93 \pm 9$ & 20.0 & 0.37 & 0.42 \\
\hline & 2 & & & $93 \pm 9$ & 48.8 & 0.45 & 0.52 \\
\hline & 3 & & & $186 \pm 19$ & 115.0 & 0.50 & 0.58 \\
\hline & 4 & & & $269 \pm 20$ & 241.3 & 0.53 & 0.62 \\
\hline & 5 & & & $269 \pm 20$ & 403.8 & 0.54 & 0.63 \\
\hline \multirow[t]{4}{*}{ SOA06-6 } & 1 & $273.0 \pm 0.1$ & $74-71$ & $89 \pm 9$ & 22.5 & 0.53 & 0.44 \\
\hline & 2 & & & $95 \pm 9$ & 56.3 & 0.65 & 0.54 \\
\hline & 3 & & & $269 \pm 20$ & 195.0 & 0.75 & 0.62 \\
\hline & 4 & & & $269 \pm 20$ & 338.8 & 0.77 & 0.64 \\
\hline SOA06-7 & 1 & $273.0 \pm 0.1$ & $70-66$ & $53 \pm 5$ & 17.5 & - & 0.41 \\
\hline SOA06-8 & 1 & $273.0 \pm 0.2$ & $70-68$ & $52 \pm 5$ & 21.3 & - & 0.43 \\
\hline SOA06-9 & 1 & $273.1 \pm 0.1$ & $70-68$ & $54 \pm 5$ & 18.8 & - & 0.42 \\
\hline SOA06-10 & 1 & $273.2 \pm 0.1$ & $71-64$ & $54 \pm 5$ & 20.0 & - & 0.42 \\
\hline \multirow[t]{5}{*}{ SOA03-6 } & 1 & $253.2 \pm 0.5$ & $72-67$ & $92 \pm 9$ & 50.0 & 0.99 & 0.95 \\
\hline & 2 & & & $93 \pm 9$ & 126.3 & 1.04 & 1.02 \\
\hline & 3 & & & $184 \pm 18$ & 277.5 & 1.06 & 1.05 \\
\hline & 4 & & & $269 \pm 20$ & 511.3 & 1.07 & 1.06 \\
\hline & 5 & & & $269 \pm 20$ & 746.3 & 1.07 & 1.06 \\
\hline \multirow[t]{5}{*}{ SOA05-7 } & 1 & $252.9 \pm 0.2$ & $0.16-0.18$ & $46 \pm 5$ & 21.3 & 0.77 & - \\
\hline & 2 & & & $94 \pm 9$ & 81.3 & 0.92 & - \\
\hline & 3 & & & $187 \pm 19$ & 221.3 & 0.96 & - \\
\hline & 4 & & & $269 \pm 20$ & 428.8 & 0.97 & 1.07 \\
\hline & 5 & & & $269 \pm 20$ & 636.3 & 0.98 & 1.07 \\
\hline \multirow[t]{5}{*}{ SOA05-8 } & 1 & $253.0 \pm 0.2$ & $69-66$ & $45 \pm 5$ & 25.0 & 0.93 & 0.86 \\
\hline & 2 & & & $94 \pm 9$ & 117.5 & 1.11 & 1.02 \\
\hline & 3 & & & $188 \pm 19$ & 315.0 & 1.15 & 1.06 \\
\hline & 4 & & & $269 \pm 20$ & 610.0 & 1.16 & 1.07 \\
\hline & 5 & & & $269 \pm 20$ & 818.8 & 1.16 & 1.07 \\
\hline \multirow[t]{4}{*}{ SOA05-9 } & 1 & $243.1 \pm 0.2$ & $72-70$ & $47 \pm 5$ & 38.8 & 1.12 & 1.24 \\
\hline & 2 & & & $94 \pm 9$ & 126.3 & 1.21 & 1.34 \\
\hline & 3 & & & $179 \pm 18$ & 348.8 & 1.24 & 1.37 \\
\hline & 4 & & & $269 \pm 20$ & 616.3 & 1.25 & 1.37 \\
\hline \multirow[t]{4}{*}{ SOA05-10 } & 1 & $243.1 \pm 0.2$ & $7.5-8.2$ & $47 \pm 5$ & 33.8 & 1.10 & - \\
\hline & 2 & & & $94 \pm 9$ & 106.3 & 1.20 & - \\
\hline & 3 & & & $182 \pm 18$ & 287.5 & 1.24 & - \\
\hline & 4 & & & $269 \pm 20$ & 551.3 & 1.25 & - \\
\hline SOA06-12 & 1 & $243.9 \pm 0.8$ & $78-64$ & $32 \pm 3$ & 17.5 & - & 1.08 \\
\hline SOA06-13 & 1 & $243.5 \pm 0.2$ & $70-69$ & $32 \pm 3$ & 23.8 & - & - \\
\hline SOA06-14 & 1 & $243.5 \pm 0.2$ & 58 & $31 \pm 3$ & 18.8 & - & - \\
\hline
\end{tabular}


Table A2. Experimental conditions of experiments with limonene and SOA yields calculated.

\begin{tabular}{|c|c|c|c|c|c|c|c|}
\hline Exp.-No. & Step $^{\mathrm{e}}$ & $\begin{array}{l}T \\
{[\mathrm{~K}]}\end{array}$ & $\begin{array}{l}\mathrm{RH}^{\mathrm{d}} \\
{[\%]}\end{array}$ & $\begin{array}{l}\text { Terpene }^{\mathrm{c}} \\
{\left[\mu \mathrm{g} \mathrm{m}^{-3}\right]}\end{array}$ & $\begin{array}{l}\mathrm{M}_{\text {Org }}^{\mathrm{f}} \\
{\left[\mu \mathrm{g} \mathrm{m}^{-3}\right]}\end{array}$ & $\begin{array}{l}\text { SOA Yieldg } \\
\text { individual }\end{array}$ & $\begin{array}{l}\text { SOA Yield } \\
\text { average }\end{array}$ \\
\hline \multirow[t]{5}{*}{ SOA03-10 } & 1 & $313.3 \pm 0.5$ & 20 & $92 \pm 9$ & 28 & 0.32 & 0.34 \\
\hline & 2 & & & $90 \pm 9$ & 51 & 0.38 & 0.40 \\
\hline & 3 & & & $180 \pm 18$ & 84 & 0.43 & 0.45 \\
\hline & 4 & & & $262 \pm 20$ & 172 & 0.49 & 0.51 \\
\hline & 5 & & & $262 \pm 20$ & 210 & 0.50 & 0.52 \\
\hline \multirow[t]{2}{*}{ SOA06-4 } & 1 & $303.0 \pm 0.1$ & $45-41$ & $223 \pm 20$ & 59 & 0.29 & 0.49 \\
\hline & 2 & & & $223 \pm 20$ & 110 & 0.31 & 0.56 \\
\hline \multirow[t]{5}{*}{ SOA03-8 } & 1 & $293.4 \pm 0.5$ & 40 & $88 \pm 9$ & 56 & 0.60 & 0.57 \\
\hline & 2 & & & $90 \pm 9$ & 98 & 0.66 & 0.63 \\
\hline & 3 & & & $179 \pm 18$ & 166 & 0.71 & 0.68 \\
\hline & 4 & & & $262 \pm 20$ & 290 & 0.74 & 0.71 \\
\hline & 5 & & & $262 \pm 20$ & 477 & 0.76 & 0.73 \\
\hline \multirow[t]{5}{*}{ SOA05-3 } & 1 & $293.3 \pm 0.2$ & $0.02-0.03$ & $77 \pm 8$ & 28 & 0.47 & - \\
\hline & 2 & & & $78 \pm 8$ & 64 & 0.57 & - \\
\hline & 3 & & & $182 \pm 18$ & 122 & 0.63 & - \\
\hline & 4 & & & $222 \pm 20$ & 228 & 0.67 & - \\
\hline & 5 & & & $222 \pm 20$ & 347 & 0.69 & - \\
\hline \multirow[t]{5}{*}{ SOA05-4 } & 1 & $293.2 \pm 0.2$ & 44-39 & $78 \pm 8$ & 48 & 0.54 & 0.55 \\
\hline & 2 & & & $78 \pm 8$ & 83 & 0.60 & 0.62 \\
\hline & 3 & & & $155 \pm 16$ & 155 & 0.65 & 0.67 \\
\hline & 4 & & & $223 \pm 20$ & 283 & 0.68 & 0.71 \\
\hline & 5 & & & $223 \pm 20$ & 380 & 0.69 & 0.72 \\
\hline \multirow[t]{4}{*}{ SOA06-5 } & 1 & $273.2 \pm 0.3$ & 70 & $78 \pm 8$ & 46 & 0.76 & 0.75 \\
\hline & 2 & & & $78 \pm 8$ & 112 & 0.84 & 0.84 \\
\hline & 3 & & & $223 \pm 20$ & 288 & 0.88 & 0.89 \\
\hline & 4 & & & $223 \pm 20$ & 480 & 0.89 & 0.90 \\
\hline \multirow[t]{5}{*}{ SOA03-7 } & 1 & $273.3 \pm 0.5$ & 34 & $90 \pm 9$ & 47 & - & 0.75 \\
\hline & 2 & & & $88 \pm 9$ & 117 & - & 0.84 \\
\hline & 3 & & & $181 \pm 18$ & 246 & - & 0.88 \\
\hline & 4 & & & $262 \pm 20$ & 444 & - & 0.90 \\
\hline & 5 & & & $262 \pm 20$ & 739 & - & 0.91 \\
\hline \multirow[t]{5}{*}{ SOA05-5 } & 1 & $252.8 \pm 0.2$ & $44-42$ & $36 \pm 4$ & 14 & 0.80 & 0.82 \\
\hline & 2 & & & $76 \pm 8$ & 93 & 1.04 & 1.03 \\
\hline & 3 & & & $153 \pm 15$ & 278 & 1.07 & 1.07 \\
\hline & 4 & & & $223 \pm 20$ & 481 & 1.08 & 1.08 \\
\hline & 5 & & & $223 \pm 20$ & 730 & 1.09 & 1.08 \\
\hline \multirow[t]{5}{*}{ SOA05-6 } & 1 & $252.8 \pm 0.2$ & $0.29-0.32$ & $38 \pm 4$ & 20 & 0.65 & - \\
\hline & 2 & & & $77 \pm 8$ & 60 & 0.75 & - \\
\hline & 3 & & & $154 \pm 15$ & 168 & 0.79 & - \\
\hline & 4 & & & $223 \pm 20$ & 342 & 0.80 & - \\
\hline & 5 & & & $223 \pm 20$ & 504 & 0.80 & - \\
\hline
\end{tabular}

If not stated otherwise all experiments were done with about $500 \mathrm{ppm}$ cyclohexane as $\mathrm{OH}$ scavenger and $100-300$ ppb of ozone at total pressures between 990 and $1015 \mathrm{hPa}$. ${ }^{\text {a No }}$ cyclohexane added. ${ }^{\mathrm{b}}$ 2-Butanol used as $\mathrm{OH}$ scavenger. ${ }^{\mathrm{c}}$ Amounts added to the simulation chamber. ${ }^{\mathrm{d}}$ During the experiments the relative humidity was changed by adding dry air to replace sample losses. ${ }^{\mathrm{e}}$ Steps of subsequent addition of terpene to the reaction system. ${ }^{\mathrm{f}}$ Maximum amount of organic aerosol mass present in that reaction step $\left(\rho=1.3 \mathrm{~g} \mathrm{~cm}{ }^{-3}\right.$ ). $\mathrm{g}$ Yields as calculated using Eq. (1) with the individual values determined for $\alpha_{i}$ and $K_{i}$ (c.f. Table 2). ${ }^{\text {h }}$ Yields as calculated using Eqs. (1, 12, 13, 16, 17) with the parameterised values for $\alpha_{i}$ and $K_{i}$ for humid conditions and with cyclohexane as scavenger. 
Acknowledgements. This work was supported by the ESF programme INTROP, Interdisciplinary Tropospheric Research: from the Laboratory to Global Change and the European Network of Excellence ACCENT. We thank the AIDA team of Research Centre Karlsruhe for the effective support during the measurement campaigns. $\mathrm{MH}$ and ÅMJ acknowledge support by the Swedish Foundation for Strategic Environmental Research MISTRA and Formas under contract 214-2006-1204.

Edited by: J. Seinfeld

\section{References}

Alfarra, M. R., Paulsen, D., Gysel, M., Garforth, A. A., Dommen, J., Prévôt, A. S. H., Worsnop, D. R., Baltensperger, U., and Coe, H.: A mass spectrometric study of secondary organic aerosols formed from the photooxidation of anthropogenic and biogenic precursors in a reaction chamber, Atmos. Chem. Phys., 6, 5279 5293, 2006, http://www.atmos-chem-phys.net/6/5279/2006/.

Atkinson, R., Winer, A. M., and Pitts Jr., J. N.: Rate constants for the gas-phase reactions of $\mathrm{O}_{3}$ with the natural hydrocarbons isoprene and $\alpha$-pinene and $\beta$-pinene, Atmos. Environ., 16, 1017 1020, 1982.

Atkinson, R.: Gas-phase tropospheric chemistry of volatile organic compounds .1. Alkanes and alkenes, J. Phys. Chem. Ref. Data, 26, 215-290, 1997.

Bahreini, R., Keywood, M. D., Ng, N. L., Varutbangkul, V., Gao, S., Flagan, R. C., Seinfeld, J. H., Worsnop, D. R., and Jimenez, J. L.: Measurements of secondary organic aerosol from oxidation of cycloalkenes, terpenes, and m-xylene using an Aerodyne aerosol mass spectrometer, Environ. Sci. Technol., 39, 5674-5688, 2005.

Berndt, T., Böge, O., and Stratmann, F.: Gas-phase ozonolysis of $\alpha$-pinene: gaseous products and particle formation, Atmos. Environ., 37, 3933-3945, 2003.

Bilde, M. and Pandis, S. N.: Evaporation rates and vapor pressures of individual aerosol species formed in the atmospheric oxidation of $\alpha$ - and $\beta$-pinene, Environ. Sci. Technol., 35, 3344-3349, 2001.

Bilde, M., Svenningsson, B., Monster, J., and Rosenorn, T.: Evenodd alternation of evaporation rates and vapor pressures of C3C9 dicarboxylic acid aerosols, Environ. Sci. Technol., 37, 13711378, 2003.

Bonn, B., Schuster, G., and Moortgat, G. K.: Influence of water vapor on the process of new particle formation during monoterpene ozonolysis, J. Phys. Chem. A, 106, 2869-2881, 2002.

Bowman, F. M., Odum, J. R., Seinfeld, J. H., and Pandis, S. N.: Mathematical model for gas-particle partitioning of secondary organic aerosols, Atmos. Environ., 31, 3921-3931, 1997.

Bunz, H. and Dlugi, R.: Numerical Studies on the Behavior of Aerosols in Smog Chambers, J. Aerosol Sci, 22, 441-465, 1991.

Cahill, T. M., Seaman, V. Y., Charles, M. J., Holzinger, R., and Goldstein, A. H.: Secondary organic aerosols formed from oxidation of biogenic volatile organic compounds in the Sierra Nevada Mountains of California, J. Geophys. Res.-Atmos., 111, D16312, doi:16310.11029/12006JD007178, 2006.

Cai, X. Y. and Griffin, R. J.: Theoretical modeling of the sizedependent influence of surface tension on the absorptive partitioning of semi-volatile organic compounds, J. Atmos. Chem., 50, 139-158, 2005.
Calogirou, A., Larsen, B. R., and Kotzias, D.: Gas-phase terpene oxidation products: a review, Atmos. Environ., 33, 1423-1439, 1999.

Capouet, M. and Müller, J.-F.: A group contribution method for estimating the vapour pressures of $\alpha$-pinene oxidation products, Atmos. Chem. Phys., 6, 1455-1467, 2006, http://www.atmos-chem-phys.net/6/1455/2006/.

Chattopadhyay, S. and Ziemann, P. J.: Vapor pressures of substituted and unsubstituted monocarboxylic and dicarboxylic acids measured using an improved thermal desorption particle beam mass spectrometry method, Aerosol Sci. Technol., 39, 1085-1100, 2005

Cocker, D. R., Clegg, S. L., Flagan, R. C., and Seinfeld, J. H.: The effect of water on gas-particle partitioning of secondary organic aerosol. Part I: $\alpha$-pinene/ozone system, Atmos. Environ., 35, 6049-6072, 2001.

Dahneke, B.: Simple Kinetic Theory of Brownian Diffusion in Vapors and Aerosols, Theory of Dispersed Multiphase Flow, edited by: Meyer, R. E., Academic Press, New York, 97-133 pp., 1983.

DeCarlo, P. F., Slowik, J. G., Worsnop, D. R., Davidovits, P., and Jimenez, J. L.: Particle morphology and density characterization by combined mobility and aerodynamic diameter measurements. Part 1: Theory, Aerosol Sci. Technol., 38, 1185-1205, 2004.

Docherty, K. S., Wu, W., Lim, Y. B., and Ziemann, P. J.: Contributions of organic peroxides to secondary aerosol formed from reactions of monoterpenes with $\mathrm{O}_{3}$, Environ. Sci. Technol., 39, 4049-4059, 2005.

Fredenslund, A., Gmehling, J., and Rasmussen, P.: Vapor-Liquid Equilibria Using UNIFAC: A Group-Contribution Method, Elsevier Scientific Publishing, New York, 380 pp., 1977.

Gao, S., Ng, N. L., Keywood, M., Varutbangkul, V., Bahreini, R., Nenes, A., He, J. W., Yoo, K. Y., Beauchamp, J. L., Hodyss, R. P., Flagan, R. C., and Seinfeld, J. H.: Particle phase acidity and oligomer formation in secondary organic aerosol, Environ. Sci. Technol., 38, 6582-6589, 2004.

Glasius, M., Lahaniati, M., Calogirou, A., Di Bella, D., Jensen, N. R., Hjorth, J., Kotzias, D., and Larsen, B. R.: Carboxylic acids in secondary aerosols from oxidation of cyclic monoterpenes by ozone, Environ. Sci. Technol., 34, 1001-1010, 2000.

Griffin, R. J., Cocker, D. R., Flagan, R. C., and Seinfeld, J. H.: Organic aerosol formation from the oxidation of biogenic hydrocarbons, J. Geophys. Res.-Atmos., 104, 3555-3567, 1999a.

Griffin, R. J., Cocker, D. R., Seinfeld, J. H., and Dabdub, D. Estimate of global atmospheric organic aerosol from oxidation of biogenic hydrocarbons, Geophys. Res. Lett., 26, 2721-2724, 1999b.

Griffin, R. J., Dabdub, D., and Seinfeld, J. H.: Development and initial evaluation of a dynamic species-resolved model for gas phase chemistry and size-resolved gas/particle partitioning associated with secondary organic aerosol formation, J. Geophys. Res.-Atmos., 110, D05304, doi:05310.01029/02004JD005219, 2005.

Guenther, A., Hewitt, C. N., Erickson, D., Fall, R., Geron, C., Graedel, T., Harley, P., Klinger, L., Lerdau, M., Mckay, W. A., Pierce, T., Scholes, B., Steinbrecher, R., Tallamraju, R., Taylor, J., and Zimmerman, P.: A Global-Model of Natural Volatile Organic-Compound Emissions, J. Geophys. Res.-Atmos., 100, 8873-8892, 1995 
Hallquist, M., Wängberg, I., and Ljungström, E.: Atmospheric fate of carbonyl oxidation products originating from $\alpha$-pinene and $\Delta^{3}$-carene: Determination of rate of reaction with $\mathrm{OH}$ and $\mathrm{NO}_{3}$ radicals, UV absorption cross sections, and vapor pressures, Environ. Sci. Technol., 31, 3166-3172, 1997.

Hamilton, J. F., Lewis, A. C., Carey, T. J., and Wenger, J. C.: Characterization of polar compounds and oligomers in secondary organic aerosol using liquid chromatography coupled to mass spectrometry, Anal. Chem., 80, 474-480, 2008.

Heald, C. L., Jacob, D. J., Park, R. J., Russell, L. M., Huebert, B. J., Seinfeld, J. H., Liao, H., and Weber, R. J.: A large organic aerosol source in the free troposphere missing from current models, Geophys. Res. Lett., 32, L18809, doi:18810.11029/12005GL023831, 2005.

Hoffmann, T., Odum, J. R., Bowman, F., Collins, D., Klockow, D., Flagan, R. C., and Seinfeld, J. H.: Formation of organic aerosols from the oxidation of biogenic hydrocarbons, J. Atmos. Chem., 26, 189-222, 1997.

Hoppel, W., Fitzgerald, J., Frick, G., Caffrey, P., Pasternack, L., Hegg, D., Gao, S., Leaitch, R., Shantz, N., Cantrell, C., Albrechcinski, T., Ambrusko, J., and Sullivan, W.: Particle formation and growth from ozonolysis of $\alpha$-pinene, J. Geophys. Res.Atmos., 106, 27603-27618, 2001.

Iinuma, Y., Böge, O., Gnauk, T., and Herrmann, H.: Aerosolchamber study of the $\alpha$-pinene $/ \mathrm{O}_{3}$ reaction: influence of particle acidity on aerosol yields and products, Atmos. Environ., 38, 761-773, 2004.

Iinuma, Y., Boge, O., Miao, Y., Sierau, B., Gnauk, T., and Herrmann, H.: Laboratory studies on secondary organic aerosol formation from terpenes, Faraday Discuss., 130, 279-294, 2005.

Iinuma, Y., Muller, C., Boge, O., Gnauk, T., and Herrmann, H.: The formation of organic sulfate esters in the limonene ozonolysis secondary organic aerosol (SOA) under acidic conditions, Atmos. Environ., 41, 5571-5583, 2007.

Jang, M. S., Carroll, B., Chandramouli, B., and Kamens, R. M.: Particle growth by acid-catalyzed heterogeneous reactions of organic carbonyls on preexisting aerosols, Environ. Sci. Technol., 37, 3828-3837, 2003.

Jenkin, M. E.: Modelling the formation and composition of secondary organic aerosol from $\alpha$ - and $\beta$-pinene ozonolysis using MCM v3, Atmos. Chem. Phys., 4, 1741-1757, 2004, http://www.atmos-chem-phys.net/4/1741/2004/.

Johnson, D. and Marston, G.: The gas-phase ozonolysis of unsaturated volatile organic compounds in the troposphere, Chem. Soc. Rev., 37, 699-716, doi:10.1039/b704260b, 2008.

Jonsson, A. M., Hallquist, M., and Ljungström, E.: Impact of humidity on the ozone initiated oxidation of limonene, $\Delta^{3}$-carene, and $\alpha$-pinene, Environ. Sci. Technol., 40, 188-194, 2006.

Jonsson, Å. M., Hallquist, M., and Saathoff, H.: Volatility of secondary organic aerosols from the ozone initiated oxidation of $\alpha$ pinene and limonene, J. Aerosol Sci., 38, 843-852, 2007.

Jonsson, Å. M., Hallquist, M., and Ljungstrom, E.: Influence of OH scavenger on the water effect on secondary organic aerosol formation from ozonolysis of limonene, $\Delta^{3}$-carene, and $\alpha$-pinene, Environ. Sci. Technol., 42, 5938-5944, 2008a.

Jonsson, Å. M., Hallquist, M., and Ljungstrm, E.: The effect of temperature and water on secondary organic aerosol formation from ozonolysis of limonene, $\Delta^{3}$-carene and $\alpha$-pinene, Atmos. Chem. Phys., 8, 6541-6549, 2008b, http://www.atmos-chem-phys.net/8/6541/2008/.

Kalberer, M., Paulsen, D., Sax, M., Steinbacher, M., Dommen, J., Prevot, A. S. H., Fisseha, R., Weingartner, E., Frankevich, V., Zenobi, R., and Baltensperger, U.: Identification of polymers as major components of atmospheric organic aerosols, Science, 303, 1659-1662, 2004.

Kanakidou, M., Seinfeld, J. H., Pandis, S. N., Barnes, I., Dentener, F. J., Facchini, M. C., Van Dingenen, R., Ervens, B., Nenes, A., Nielsen, C. J., Swietlicki, E., Putaud, J. P., Balkanski, Y., Fuzzi, S., Horth, J., Moortgat, G. K., Winterhalter, R., Myhre, C. E. L., Tsigaridis, K., Vignati, E., Stephanou, E. G., and Wilson, J.: Organic aerosol and global climate modelling: a review, Atmos. Chem. Phys., 5, 1053-1123, 2005,

http://www.atmos-chem-phys.net/5/1053/2005/.

Keywood, M. D., Kroll, J. H., Varutbangkul, V., Bahreini, R., Flagan, R. C., and Seinfeld, J. H.: Secondary organic aerosol formation from cyclohexene ozonolysis: Effect of $\mathrm{OH}$ scavenger and the role of radical chemistry, Environ. Sci. Technol., 38, 3343-3350, 2004.

Khamaganov, V. G. and Hites, R. A.: Rate constants for the gasphase reactions of ozone with isoprene, $\alpha$ - and $\beta$-pinene, and limonene as a function of temperature, J. Phys. Chem. A, 105, 815-822, 2001.

Koch, S., Winterhalter, R., Uherek, E., Kolloff, A., Neeb, P., and Moortgat, G. K.: Formation of new particles in the gas-phase ozonolysis of monoterpenes, Atmos. Environ., 34, 4031-4042, 2000.

Kostenidou, E., Pathak, R. K., and Pandis, S. N.: An Algorithm for the Calculation of Secondary Organic Aerosol Density Combining AMS and SMPS Data, Aerosol Sci. Technol., 41, 1002-1010, 2007.

Kroll, J. H., Chan, A. W. H., Ng, N. L., Flagan, R. C., and Seinfeld, J. H.: Reactions of semivolatile organics and their effects on secondary organic aerosol formation, Environ. Sci. Technol., 41, 3545-3550, 2007.

Leungsakul, S., Jaoui, M., and Kamens, R. M.: Kinetic mechanism for predicting secondary organic aerosol formation from the reaction of d-limonene with ozone, Environ. Sci. Technol., 39, 9583-9594, 2005.

Matsunaga, S. N., Wiedinmyer, C., Guenther, A. B., Orlando, J. J., Karl, T., Toohey, D. W., Greenberg, J. P., and Kajii, Y.: Isoprene oxidation products are a significant atmospheric aerosol component, Atmos. Chem. Phys. Discuss., 5, 11143-11156, 2005, http://www.atmos-chem-phys-discuss.net/5/11143/2005/.

Müller, J. F.: Geographical-Distribution and Seasonal-Variation of Surface Emissions and Deposition Velocities of Atmospheric Trace Gases, J. Geophys. Res.-Atmos., 97, 3787-3804, 1992.

Naumann, K. H.: COSIMA - a computer program simulating the dynamics of fractal aerosols, J. Aerosol Sci., 34, 1371-1397, 2003.

Naumann, K. H.: COSIMA-SOA - a model to simulate formation and dynamics of secondary organic aerosol, J. Aerosol Sci., in preparation, 2009.

Northcross, A. L. and Jang, M.: Heterogeneous SOA yield from ozonolysis of monoterpenes in the presence of inorganic acid, Atmos. Environ., 41, 1483-1493, 2007. 
Odum, J. R., Hoffmann, T., Bowman, F., Collins, D., Flagan, R. C., and Seinfeld, J. H.: Gas/particle partitioning and secondary organic aerosol yields, Environ. Sci. Technol., 30, 2580-2585, 1996.

Offenberg, J. H., Kleindienst, T. E., Jaoui, M., Lewandowski, M., and Edney, E. O.: Thermal properties of secondary organic aerosols, Geophys. Res. Lett., 33, L03816, doi:03810.01029/02005GL024623, 2006.

Pankow, J. F.: An Absorption-Model of the Gas Aerosol Partitioning Involved in the Formation of Secondary Organic Aerosol, Atmos. Environ., 28, 189-193, 1994.

Pathak, R. K., Presto, A. A., Lane, T. E., Stanier, C. O., Donahue, N. M., and Pandis, S. N.: Ozonolysis of $\alpha$-pinene: parameterization of secondary organic aerosol mass fraction, Atmos. Chem. Phys., 7, 3811-3821, 2007a,

http://www.atmos-chem-phys.net/7/3811/2007/.

Pathak, R. K., Presto, A. A., Lane, T. E., Stanier, C. O., Donahue, N. M., and Pandis, S. N.: Ozonolysis of $\alpha$-pinene: parameterization of secondary organic aerosol mass fraction, Atmos. Chem. Phys., 7, 3811-3821, 2007b,

http://www.atmos-chem-phys.net/7/3811/2007/.

Plewka, A., Gnauk, T., Bru"ggemann, E., and Herrmann, H.: Biogenic contributions to the chemical composition of airborne particles in a coniferous forest in Germany, Atmos. Environ., 40, S103-S115, 2006.

Poling, B. E., Prausnitz, J. M., and Reid, R. C.: The Properties of Gases and Liquids, 4 ed., McGraw-Hill, New York, 581 pp., 1987.

Presto, A. A. and Donahue, N. M.: Investigation of $\alpha$-pinene plus ozone secondary organic aerosol formation at low total aerosol mass, Environ. Sci. Technol., 40, 3536-3543, 2006.

Saathoff, H., Moehler, O., Schurath, U., Kamm, S., Dippel, B., and Mihelcic, D.: The AIDA soot aerosol characterisation campaign 1999, J. Aerosol Sci, 34, 1277-1296, 2003.

Seinfeld, J. H. and Pankow, J. F.: Organic atmospheric particulate material, Annu. Rev. Phys. Chem., 54, 121-140, 2003.

Sheehan, P. E. and Bowman, F. M.: Estimated effects of temperature on secondary organic aerosol concentrations, Environ. Sci. Technol., 35, 2129-2135, 2001.

Shilling, J. E., Chen, Q., King, S. M., Rosenoern, T., Kroll, J. H., Worsnop, D. R., McKinney, K. A., and Martin, S. T.: Particle mass yield in secondary organic aerosol formed by the dark ozonolysis of $\alpha$-pinene, Atmos. Chem. Phys., 8, 2073-2088, 2008, http://www.atmos-chem-phys.net/8/2073/2008/.

Simpson, D., Yttri, K. E., Klimont, Z., Kupiainen, K., Caseiro, A., Gelencser, A., Pio, C., Puxbaum, H., and Legrand, M.: Modeling carbonaceous aerosol over Europe: Analysis of the CARBOSOL and EMEP EC/OC campaigns, J. Geophys. Res.-Atmos., 112, D23S14, doi:10.1029/2006JD008158, 2007.

Song, C., Zaveri, R. A., Alexander, M. L., Thornton, J. A., Madronich, S., Ortega, J. V., Zelenyuk, A., Yu, X. Y., Laskin, A., and Maughan, D. A.: Effect of hydrophobic primary organic aerosols on secondary organic aerosol formation from ozonolysis of $\alpha$-pinene, Geophys. Res. Lett., 34, L20803, doi:20810.21029/22007GL030720, 2007.
Stanier, C. O., Pathak, R. K., and Pandis, S. N.: Measurements of the volatility of aerosols from $\alpha$-piniene ozonolysis, Environ. Sci. Technol., 41, 2756-2763, 2007.

Svendby, T. M., Lazaridis, M., and Torseth, K.: Temperature dependent secondary organic aerosol formation from terpenes and aromatics, J. Atmos. Chem., 59, 25-46, 2008.

Takekawa, H., Minoura, H., and Yamazaki, S.: Temperature dependence of secondary organic aerosol formation by photo-oxidation of hydrocarbons, Atmos. Environ., 37, 3413-3424, 2003.

Tillmann, R., Saathoff, H., Brauers, T., Kiendler-Scharr, A., and Mentel, T. F.: Rate constants for the gas phase ozonolysis of $\alpha$-pinene in the temperature range of 243-303 K, Phys. Chem. Chem. Phys., doi:10.1039/B813407C, 2008.

Tillmann, R., Kiendler-Scharr, A., Mentel, T., Jonsson, Å. M., Hallquist, M., Iinuma, Y., and Saathoff, H.: Water and Temperature Dependence of Pinonaldehyde and $\mathrm{OH}$ yields from Ozonolyis of $\alpha$-pinene, Atmos. Chem. Phys. Discuss., in preparation, 2009.

Tsigaridis, K., Lathière, J., Kanakidou, M., and Hauglustaine, D. A.: Naturally driven variability in the global secondary organic aerosol over a decade, Atmos. Chem. Phys., 5, 1891-1904, 2005, http://www.atmos-chem-phys.net/5/1891/2005/.

Tsigaridis, K., and Kanakidou, M.: Secondary organic aerosol importance in the future atmosphere, Atmos. Environ., 41, 46824692, 2007.

Walser, M. L., Desyaterik, Y., Laskin, J., Laskin, A., and Nizkorodov, S. A.: High-resolution mass spectrometric analysis of secondary organic aerosol produced by ozonation of limonene, Phys. Chem. Chem. Phys., 10, 1009-1022, 2008.

Wentzel, M., Gorzawski, H., Naumann, K. H., Saathoff, H., and Weinbruch, S.: Transmission electron microscopical and aerosol dynamical characterization of soot aerosols, J. Aerosol Sci., 34, 1347-1370, 2003

Wirtz, K. and Martin-Reviejo, M.: Density of secondary organic aerosols, J. Aerosol Sci., 34, S223-S224, 2003.

Yu, J. Z., Cocker, D. R., Griffin, R. J., Flagan, R. C., and Seinfeld, J. H.: Gas-phase ozone oxidation of monoterpenes: Gaseous and particulate products, J. Atmos. Chem., 34, 207-258, 1999a.

Yu, J. Z., Griffin, R. J., Cocker, D. R., Flagan, R. C., Seinfeld, J. H., and Blanchard, P.: Observation of gaseous and particulate products of monoterpene oxidation in forest atmospheres, Geophys. Res. Lett., 26, 1145-1148, 1999b.

Zhang, J. Y., Hartz, K. E. H., Pandis, S. N., and Donahue, N. M.: Secondary organic aerosol formation from limonene ozonolysis: Homogeneous and heterogeneous influences as a function of $\mathrm{NO}_{\mathrm{x}}$, J. Phys. Chem. A, 110, 11053-11063, 2006.

Zhang, Q., Alfarra, M. R., Worsnop, D. R., Allan, J. D., Coe, H., Canagaratna, M. R., and Jimenez, J. L.: Deconvolution and quantification of hydrocarbon-like and oxygenated organic aerosols based on aerosol mass spectrometry, Environ. Sci. Technol., 39, 4938-4952, 2005. 